\title{
QFD na garantia da qualidade do produto durante seu desenvolvimento - caso em uma empresa de materiais
}

\author{
Leonel Del Rey de Melo Filho \\ Lin ChIH Cheng \\ UFMG
}

\begin{abstract}
Resumo
Este artigo apresenta uma aplicação do método QFD em uma empresa de materiais. A intervenção foi para garantia da qualidade de um produto durante seu redesenvolvimento, em atendimento ao desejo do cliente único de ter uma característica do produto aumentada, sem prejuízo a outras. Foram efetuados dois desdobramentos associados: qualidade positiva e tecnologia do processo. A estratégia de pesquisa adotada foi a de pesquisa-ação. Utilizou-se também um guia para intervenção do QFD. O desdobramento da tecnologia mostrou como alterações na tecnologia de fabricação afetam os índices de controle do processo (foco cliente interno); enquanto o desdobramento da qualidade revelou como essas mesmas alterações afetam a qualidade do produto final ffoco cliente externo]. A técnica de planejamento e análise de experimentos auxiliou na definição das intervenções no processo e na definição de correlações. Foram levantados alguns aspectos não contemplados pelo guia de intervenção do QFD, bem como tópicos para pesquisas futuras.
\end{abstract}

Palavras-chave

Desenvolvimento de produto, QFD, desdobramento da qualidade, desdobramento da tecnologia do processo de fabricação, indústria de materiais.

\section{QFD for quality assurance during product development - a case in a materials industry}

\begin{abstract}
The article presents an application of QFD method in a materials industry. The intervention aimed at quality assurance of a product during its redevelopment, in order to respond to the desire of product client of having a quality characteristic enhanced without jeopardizing others. Two deployments were carried out in association: positive quality and process technology. This study was conducted by means of action-research. It also employed an intervention guide for QFD studies. The technology deployment showed how alterations in process technology affect process control parameters (a focus on internal client); whereas, the quality deployment revealed how these same alterations affect the final product quality (a focus on external client). Planning and Analysis of Experiments showed to be helpful in defining interventions in the process and in establishing correlations. The article ends by pointing out some aspects not contemplated by the QFD intervention guide, as well as topics for future studies.
\end{abstract}

Key words

Product development, QFD, quality deployment, technology deployment of manufacturing process, materials industry. 


\section{INTRODUĈ̣̃O}

A qualidade do produto, no sentido amplo, pode ser entendida como a satisfação da necessidade do cliente. A garantia dessa qualidade pode ser realizada através de três enfoques complementares, que fazem parte do ciclo de vida do produto: garantia da qualidade pela inspeção, garantia da qualidade pelo controle do processo e garantia da qualidade durante o desenvolvimento do produto (CHENG; MELO FILHO, 2007). Atribui-se cada vez mais atenção ao terceiro enfoque, pois o sucesso na gestão do sistema de desenvolvimento de produtos (SDP) tem-se mostrado importante para competitividade. No entanto, a gestão desse sistema tem sido pouco relatada em indústria de materiais, que é um tipo de indústria de processos (MELO FILHO, 2005; MEYER; DALAL, 2002).

A indústria de processos pode ser caracterizada por realizar transformação nas propriedades químicas e/ou físicas dos materiais, por meio de processos contínuos de fabricação ou operações unitárias (SHREVE, JUNIOR, 1997). Podemos citar como exemplos de indústria de processos: indústria petrolífera, de alimentos, produtos químicos e farmacêuticos, papel, cerâmica, metalúrgicas, cosméticos, cal, entre diversas outras.

Em geral, a produção neste tipo de indústria é realizada por equipamentos relativamente grandes, previamente condicionados, de forma que os resultados sejam otimizados (DRUMOND, 1997). São definidos as matérias-primas, os insumos, e os parâmetros de controle do processo que devem ser ajustados e monitorados por operadores, que muitas vezes atuam em uma sala de controle remoto. A escolha das especificações das matérias-primas e das faixas de operação dos parâmetros de controle, assim como o cumprimento rigoroso dessas determinações por parte dos operadores, praticamente define a qualidade do produto fabricado.

Muitas empresas de processos produzem materiais como produto final, que são utilizados como matérias-primas por outras indústrias. Este tipo de indústria de processos é denominado de indústria de materiais, que se caracteriza ainda por atuar nas primeiras etapas de uma cadeia produtiva: do substrato da natureza para o primeiro estágio de industrialização. Exemplos são: indústria petrolífera, mineradoras, maioria das metalúrgicas, celulose, sulfato de níquel, cal, entre outras. Como mencionado anteriormente, a gestão do SDP tem sido pouco relatada neste tipo de indústria. Uma das explicações se deve à dificuldade de desenvolvimento de produtos nesse setor industrial que possui processo contínuo de fabricação, e o curso das inovações de produto e de processo pode durar décadas (UTTERBACK, 1994).

Segundo Cheng e Melo Filho (2007), a GDP das empresas pode ser dividida em dois níveis: estratégico e operacional. No nível operacional, o método QFD tem sido muito utilizado na estruturação de processos de desenvolvimento de produtos, em diferentes etapas do ciclo de desenvolvimento, como: planejamento do produto, projeto do produto e do processo, e preparação para produção. O desdobramento do método mais empregado é o da qualidade positiva. Existem poucos relatos sobre aplicação dos outros desdobramentos, como tecnologia, custos e qualidade negativa. O objetivo deste artigo é relatar como os desdobramentos de qualidade positiva e de tecnologia podem ser utilizados em uma indústria de materiais. Apresenta-se uma intervenção durante o

\section{bjetivo é relatar como os desdobramentos de qualidade positiva e de tecnologia podem ser utilizados em uma indústria de materiais.}

reprojeto de um produto. Há três aspectos importantes nessa aplicação: 1- aplicação do QFD na garantia da qualidade durante o desenvolvimento de produtos em uma empresa de materiais; 2- utilização do desdobramento da qualidade positiva associada ao da tecnologia do processo de produção; e, 3- utilização da técnica de planejamento e análise de experimentos como auxiliar aos dois desdobramentos.

\section{O MÉTODO QFD}

\section{Evolução do Método}

O método QFD foi formulado pelos professores Akao e Mizuno no final da década de 60 como método capaz de auxiliar a garantia da qualidade durante o desenvolvimento do produto. Desde então, vários elementos conceituais e metodológicos foram acrescentados ao método, o que resultou num modelo amplo de QFD e num compêndio de formas alternativas de sua aplicação.

Paralelamente a essa evolução metodológica no Japão, a partir de 1986, houve nos Estados Unidos (EUA) uma difusão intensa do QFD, porém com características diferentes daquele desenvolvido pela equipe do professor Akao. A existência de variadas versões de QFD cria uma certa confusão no entendimento do que seria verdadeiramente o QFD (AKAO, 1996). A confusão acontece pelo menos em dois aspectos: nas diferentes formas de denominar o método e nas diferentes versões existentes.

O mesmo nome QFD é atribuído a conteúdos diferentes. Em geral, nos EUA e na Europa, o método se restringe ao Desdobramento da Qualidade - QD. Enquanto, no Japão, o QFD (em japonês, Hinshitsu Kino Tenkai) é composto 
de QD e QFDr, entendido de forma ampla, e ligado ao sistema de gestão de qualidade. No Brasil, com poucas exceções, verifica-se que o entendimento do QFD tem sido influenciado fortemente pela visão americana e européia.

Quanto à existência de diferentes versões do QFD, há nos EUA duas versões distintas adotadas por duas instituições diferentes. A primeira, e a mais conhecida, caracteriza-se por quatro desdobramentos principais - planejamento do produto, desdobramento dos componentes, planejamento do processo e planejamento da produção. Esta versão simplificada, que inclui somente o QD, foi adotada pelo American Supplier Institute (ASI); ela não incorporou os avanços da prática do método (CLAUSING, 1994). A segunda, difundida pela Goal/QPC de Bob King, caracteriza o QFD como um desdobramento sistemático de matrizes ao invés de tabelas; ela não faz distinção de modelos conceituais, o que na visão japonesa é um requisito básico para diferentes estudos em diferentes indústrias. de materiais (do substrato da natureza à transformação em produto comercial).

Existem estudos exploratórios e descritivos sobre como o método tem sido aplicado em alguns países, que têm trazido importantes revelações para reflexões sobre as ações do passado e do presente; e, acima de tudo, têm contribuído para redirecionar as atividades e os planos futuros da comunidade de QFD (AKAO; NAOI, 1987; GRIFFIN, 1992; VONDEREMBSE; RAGHUNATHAN, 1997; EKDAHL; GUSTAFSSON, 1997; CAUCHICK MIGUEL; CARPINETTI, 1999; CRISTIANO, LIKER; WHITE, 2000; MARTINS; ASPINWALL, 2001; CHAN; WU, 2002). Para nós, aqui do Brasil, como parte dessa grande comunidade mundial de QFD, a preocupação é como tornar o método mais eficaz, melhor compreendido e aplicado, e nisso consiste o propósito deste trabalho. Este artigo mostra como o QFD pode ser utilizado em uma empresa de materiais, na garantia da qualidade durante o reprojeto de um produto. Ele relata dois casos de utilização do QFD estilo japonês, com foco no QD, onde os modelos conceituais foram elaborados em função das contingências de cada projeto.

\section{0 que é QFD}

$O$ QFD pode ser conceituado como "uma forma de comunicar sis-

Provavelmente, a não aplicação do QFDr (QFD restrito) nos EUA se deve à existência nesse país de outros processos estabelecidos de desenvolvimento de produto. Um exemplo é o uso da Análise de Sistemas e Métodos de Engenharia de Sistemas pela General Motors (ROSS; PARYANI, 1995). As simplificações apontadas fazem com que o potencial do QFD não seja plenamente aproveitado. Entretanto, tem havido um esforço no sentido de usar todo o conteúdo do QFD, tanto nos EUA quanto na Europa, impulsionado pelo QFD Institute dos Estados Unidos. No Brasil, alguns praticantes têm utilizado as versões do ASI ou do King, porém, essas versões são simplificações do original que limitam o alcance do resultado em toda sua plenitude (CHENG; MELO FILHO, 2007).

Com relação à prática de QFD nos EUA, ela se encontra em quase todos os setores da indústria, em especial nas indústrias automobilística, de serviços e de software. $\mathrm{Na}$ Europa, o QFD é também bastante conhecido, e diversos casos de aplicação têm sido relatados. De outras partes do mundo, podemos citar as aplicações inovadoras de QFD na Austrália, na área de planejamento estratégico e desenvolvimento de novo negócio ou melhoria de negócio existente, em conjunto com o uso do método de Hoshin Kanri. No Brasil, há relatos de aplicações de QFD nas empresas automobilística e de alimentos desde 1995, mas não em indústria tematicamente informação relacionada com a qualidade e de explicitar ordenadamente trabalho relacionado com a obtenção da qualidade, tem como objetivo alcançar o enfoque da garantia da qualidade durante o desenvolvimento de produto e é subdividido em Desdobramento da Qualidade (QD) e Desdobramento da Função Qualidade no sentido restrito (QFDr)" (CHENG; MELO FILHO, 2007). A aplicação deste método tem sido feita mais nas etapas iniciais do processo de desenvolvimento de produtos. Entretanto, há uma aplicação relatada na etapa de preparação para produção (ARAÚJO, 2002), porém não na indústria de materiais.

O QD do QFD acontece em pelo menos dois planos: vertical e horizontal. Desdobrar qualidade no plano vertical, ou em maior detalhamento, é detalhar concretizando o raciocínio de causas-efeito, de forma encadeada, em vários níveis hierárquicos. As unidades operacionais básicas são: tabela, matriz, modelo conceitual e conjunto de padrões para produção. O desdobramento da qualidade na direção horizontal, ou em amplitude, contempla quatro dimensões: qualidade (positiva), tecnologia, custo e confiabilidade (qualidade negativa). A Figura 1 representa os dois planos do desdobramento. No entanto, a maioria das referências encontradas e analisadas mostra exemplos da utilização apenas do desdobramento da qualidade positiva, não sendo 
encontradas referências sobre o desdobramento da tecnologia em indústria de materiais.

O desdobramento que contempla as dimensões da qualidade e da tecnologia visa principalmente resolver, de forma antecipada, problemas relacionados a atendimento de metas de desempenho ou estreitamento das faixas de variabilidade de características de qualidade dos produtos, de parâmetros de processos de fabricação e de características de qualidade de matérias-primas. As referências bibliográficas encontradas até então mostram aplicação do desdobramento da tecnologia com foco no produto (AKAO, 1990, 1996; CHENG et al., 1995). Ou seja, foco na resolução de problemas relacionados a metas de especificação técnica do produto projetado. O presente trabalho apresenta uma sugestão de desdobramento da tecnologia associada ao da qualidade positiva, com foco no processo de fabricação, ou seja, com foco também na resolução de problemas relacionados aos índices de desempenho do processo (IDPs - como produtividade, eficiência, rendimento e disponibilidade), além daqueles relacionados ao produto, que contemple fatores relacionados ao processo de produção como: processos, parâmetros de controle dos processos, equipamentos, característica dos equipamentos e os IDPs.

Durante a aplicação do QFD, é necessário que sejam levantadas informações sobre diferentes agentes, como mercado-alvo, necessidades dos clientes e suas priorizações, análises de concorrência, grau de correlações, entre outros. Essas informações, que servem de entrada na utilização das unidades operacionais do método (tabelas, matrizes, modelos conceituais e padrões), muitas vezes não estão facilmente disponíveis ou são obtidas de fontes duvidosas, e/ou merecem um tratamento mais criterioso em relação às necessidades de quem as aplica. Para obtenção e análise dessas informações, utilizam-se técnicas estatísticas (CHENG; MELO FILHO, 2007; DRUMOND, 1997). Uma destas técnicas utilizadas no desenvolvimento de produtos é o Planejamento de Análise de Experimentos (MONTGOMERY, 1997). Há relatos de sua utilização com o QFD em empresas de alimentos, mas não como auxiliar em conjunto aos desdobramentos da qualidade e tecnologia, aplicados em indústria de materiais (CHENG; MELO FILHO, 2007; OLIVEIRA; DRUMOND, 2000).

\section{Aplicando o QFD - um guia de intervenção}

Cheng (2003) apresenta um guia de intervenção referente à operacionalização do QFD, estruturado em objetivos que se pretende alcançar com o uso do método e como as unidades básicas podem ser operacionalizadas. Ele se baseia em três perguntas e ações recomendadas. A Figura 2 resume este guia. Nos casos apresentados neste artigo, utilizou-se este

Figura 1: Os dois planos de desdobramento da qualidade.

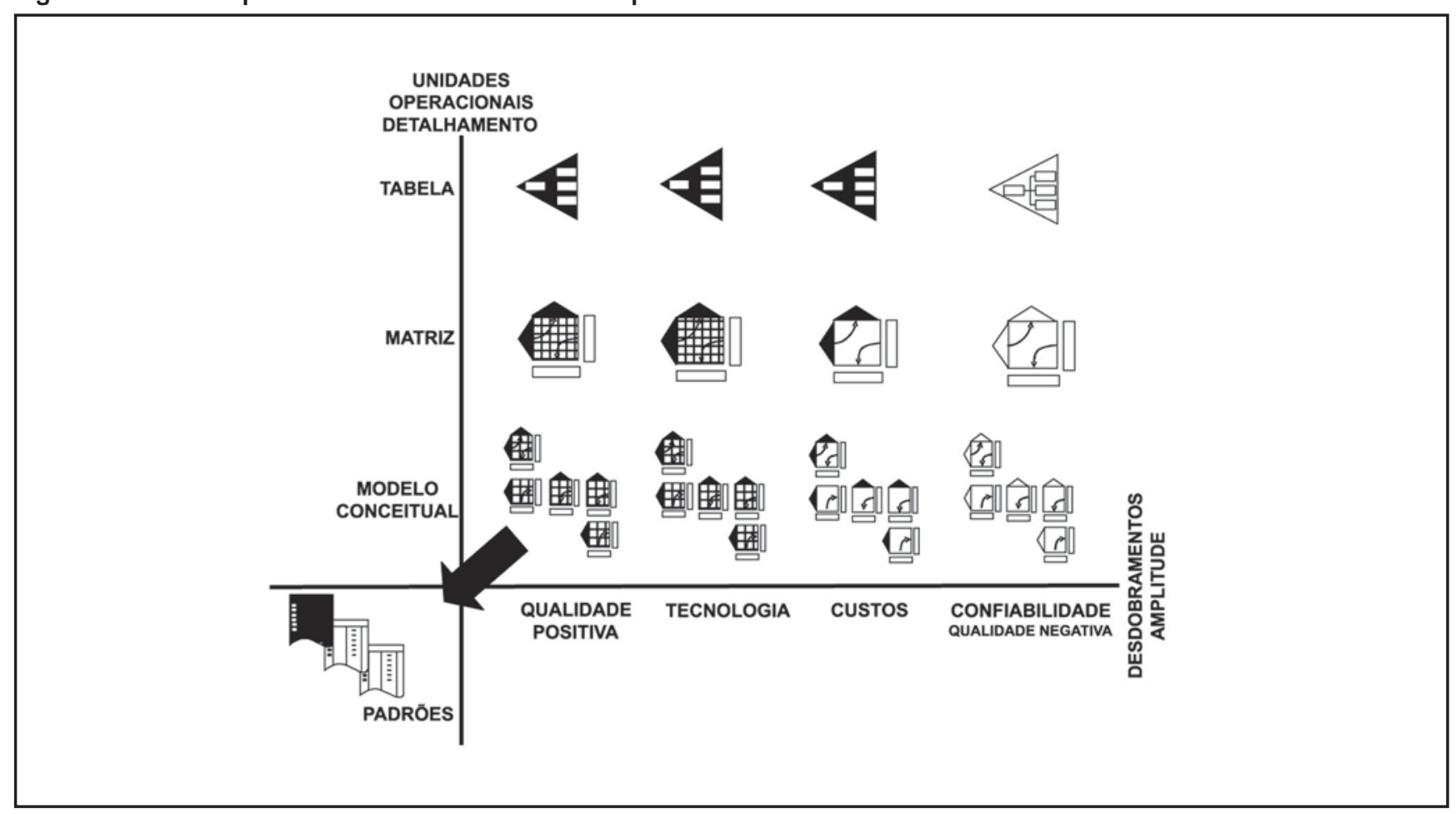

Fonte: Cheng; Melo Filho, 2007. 
guia para auxiliar a construção dos modelos conceituais, e também no desdobramento e preenchimento das matrizes. No entanto, situações não tratadas pelo guia surgiram no decorrer das aplicações e estão evidenciadas ao longo do relato dos casos e também na conclusão do trabalho.

\section{METODOLOGIA DE PESQUISA}

A estratégia de pesquisa adotada foi a pesquisa-ação. $\mathrm{O}$ conhecimento sobre o que é a pesquisa-ação e seus procedimentos operacionais já foram descritos e detalhados por diversos autores (COUGHLAN; COGHLAN, 2002; SUSMAN; EVERED, 1978; RAPOPORT, 1970). Para efeito deste trabalho, seria suficiente mencionar a definição de acordo com Rapoport (1970): “a pesquisa-ação objetiva contribuir para as necessidades práticas das pessoas que estão inseridas em situação-problema e para acumulação do conhecimento das ciências sociais dentro de uma estrutura ética de trabalho mutuamente aceitável".

O processo de intervenção durou seis meses, desenvolvido por um grupo multifuncional de sete pessoas, com uma dedicação maior do líder do grupo - em torno de vinte horas semanais. Além desse grupo, outras três pessoas também participaram das atividades. O pesquisador esteve na empresa em média dois dias por semana, onde ajudou no desenvolvimento dos trabalhos. As principais fontes de

Figura 2: Guia para intervenção ao nível operacional usando QFD.

\section{I - Qual é o objetivo a ser alcançado com o uso de QFD?}

\begin{tabular}{l|l}
\hline Tipos de situação & Recomendação \\
\hline $\begin{array}{l}\text { 1. Relacionado ao desenvolvimento de produto, visando } \\
\text { apoiar a função Marketing no refinamento da definição } \\
\text { do conceito e na realizaçnao da análise competitiva, } \\
\text { dentro das dimensões requisitos do cliente e }\end{array}$ & - Matriz da Qualidade seria suficiente \\
$\begin{array}{l}\text { características do produto. } \\
\text { 2. Relacionado ao desenvolvimento de produto, visando } \\
\begin{array}{l}\text { apoiar a função Pesquisa e Desenvolvimento no } \\
\text { projeto e especificação do produto, processos e } \\
\text { materiais, de forma que os requisitos do cliente } \\
\text { sejam alcançados. }\end{array}\end{array}$ & $\begin{array}{l}\text { - Um modelo conceitual mais elaborado seria } \\
\text { necessário }\end{array}$ \\
$\begin{array}{l}\text { 3. Relacionado à garantia de qualidade, para ajudar } \\
\text { a função Produção e entender e relacionar } \\
\text { especificaçães de produto, partes e materiais, e } \\
\text { parâmetros de controle do processo. }\end{array}$ & $\begin{array}{l}\text { Um modelo conceitual mais elaborado, incluindo } \\
\text { tabela de parâmetros de controle do processo, seria } \\
\text { necessário }\end{array}$ \\
\hline
\end{tabular}

\section{II - Como o modelo Conceitual deve ser formulado?}

\begin{tabular}{|c|c|}
\hline Tipos de Considerações & Recomendações \\
\hline $\begin{array}{l}\text { 1. Quanto ao tipo de modelo conceitual } \\
\text { 2. Quanto à lógica por trás da formulação do modelo } \\
\text { conceitual } \\
\text { 3. Quanto às características do modelo conceitual }\end{array}$ & $\begin{array}{l}\text { - Elaborar um modelo principal e modelos auxiliares } \\
\text { - Formular de acordo com o raciocínio da equipe de } \\
\text { design e desenvolvimento e/ou estágios da linha de } \\
\text { produção } \\
\text { - Levar em cosideração o objetivo do estudo, tipo de } \\
\text { indústria, tipo de organização, tipo de produto e } \\
\text { proximidade ao usuário final }\end{array}$ \\
\hline
\end{tabular}

\section{III - Como as Tabelas e Matrizes devem ser desdobradas e preenchidas?}

\begin{tabular}{l|l}
\hline Tipos de dúvida & Recomendação \\
\hline $\begin{array}{l}\text { 1. Quanto ao nível de desdobramento } \\
\text { 2. Quanto à formação da matriz }\end{array}$ & $\begin{array}{l}\text { Depende da utilidade em clarificar o que está oculto. } \\
-\end{array}$ \\
$\begin{array}{l}\text { 3. Quanto à atribuição da importância das linhas e } \\
\text { encorajadas na combinação das tabelas. }\end{array}$ & $\begin{array}{l}\text { Independe da especificação de valor }- \text { criatividade e } \\
\text { flexibilidade são encorajadas. }\end{array}$ \\
$\begin{array}{l}\text { 4. Quanto à especificação de valor das linhas e colunas } \\
\text { Independe da atribuição de importância, conhecimento } \\
\text { tecnológico específico, técnicas estatísticas e de } \\
\text { otimização são necessários. }\end{array}$
\end{tabular}


informação utilizadas no decorrer do projeto foram: dados qualitativos e quantitativos, provenientes de documentação fornecida pela empresa; informações relativas aos problemas, levantadas por observações diretas; planejamento e acompanhamento de tarefas.

Para o início, e ao longo dos trabalhos, foi necessário estruturar o problema do projeto. A estruturação realizada pode ser divida em dois níveis: pesquisador-empresa e pesquisador-pesquisador. No primeiro nível, pesquisador-empresa, o conhecimento sobre a estruturação e a sua construção foram divididos entre pesquisador e empresa, e se basearam nas questões contidas na Tabela 1.

Esta estruturação pode ser chamada de escopo do projeto, e foi baseada na teoria apresentada por Clark e Wheelwright (1993) e Cheng (2003). Já no nível pesquisador-pesquisador, o conhecimento sobre a estruturação e a sua construção pertenceram apenas ao pesquisador, e se basearam nas questões agrupadas na Tabela 2. Essas questões se fundamentaram na teoria apresentada por Checkland (1981) e Cheng (2003). As duas estruturas apresentadas possibilitaram ao pesquisador enxergar o início-meio-fim dos projetos, fundamental para um bom planejamento das atividades.

Os conhecimentos teóricos e práticos do pesquisador foram utilizados no desenvolvimento de uma estrutura em que a pesquisa-ação pudesse ser realizada na rotina da empresa. As etapas desse procedimento operacional, realizadas em cada seção de trabalho, estão listadas na Tabela 3. As três primeiras etapas foram sempre realizadas pelo líder e pesquisador juntos. Antes de toda seção de trabalho, estes se reuniam para avaliar o andamento do projeto e para definir as atividades diárias. A terceira etapa, definição das pessoas necessárias para participarem da reunião, foi muito importante, pois os trabalhos só seriam desenvolvidos com qualidade se houvesse participação efetiva dos trabalhadores que possuíam o conhecimento prático do processo.

Houve uma diferença entre o grupo principal e o grupo do trabalho. O grupo principal foi formado pelos responsáveis pelo andamento do trabalho, o qual foi definido na etapa inicial do projeto (escopo do projeto). Já o grupo de trabalho foi composto por todas as pessoas necessárias para o desenvolvimento das atividades do dia, sendo formados pelos coordenadores funcionais (CF), principalmente os dois que atuaram diretamente nas atividades, com os outros trabalhadores e o pesquisador. O pesquisador participou ativamente dos grupos de trabalho, atuando como orientador/moderador das atividades. A Figura 3 representa esse processo.

Os treinamentos propostos na etapa IV, com duração máxima de $40 \mathrm{~min}$, foram realizados com o objetivo de transmitir para os participantes que não participaram de nenhum curso a essência do método QFD: o QUÊ é, PARA que serve, e COMO utilizá-lo. Esse procedimento mostrou ser muito importante, pois os participantes passavam a compreender o PORQUÊ do projeto e PARA QUÊ servia o método. Os trabalhadores passaram a se sentir valorizados e, com isto, contribuíram com qualidade para o desenvolvimento das atividades fornecendo conhecimentos relevantes.

A 5a etapa daquele procedimento, reunir todos os membros para a reunião, foi realizada em função da rotina da empresa, necessitando que o pesquisador possuísse um grau de flexibilidade. Muitas vezes as reuniões iam aos membros, não o contrário. Não havia um local específico para realização das sessões; elas ocorriam no painel de controle, no laboratório, e em salas reservadas.

Para que as informações não se perdessem durante as atividades, o pesquisador utilizou um diário de bordo para armazená-las, de forma que o máximo de informações fosse arquivado para futuras análises. O preenchimento desse

Tabela 1: Questões utilizadas para estruturar o problema do projeto — nível pesquisador-empresa.

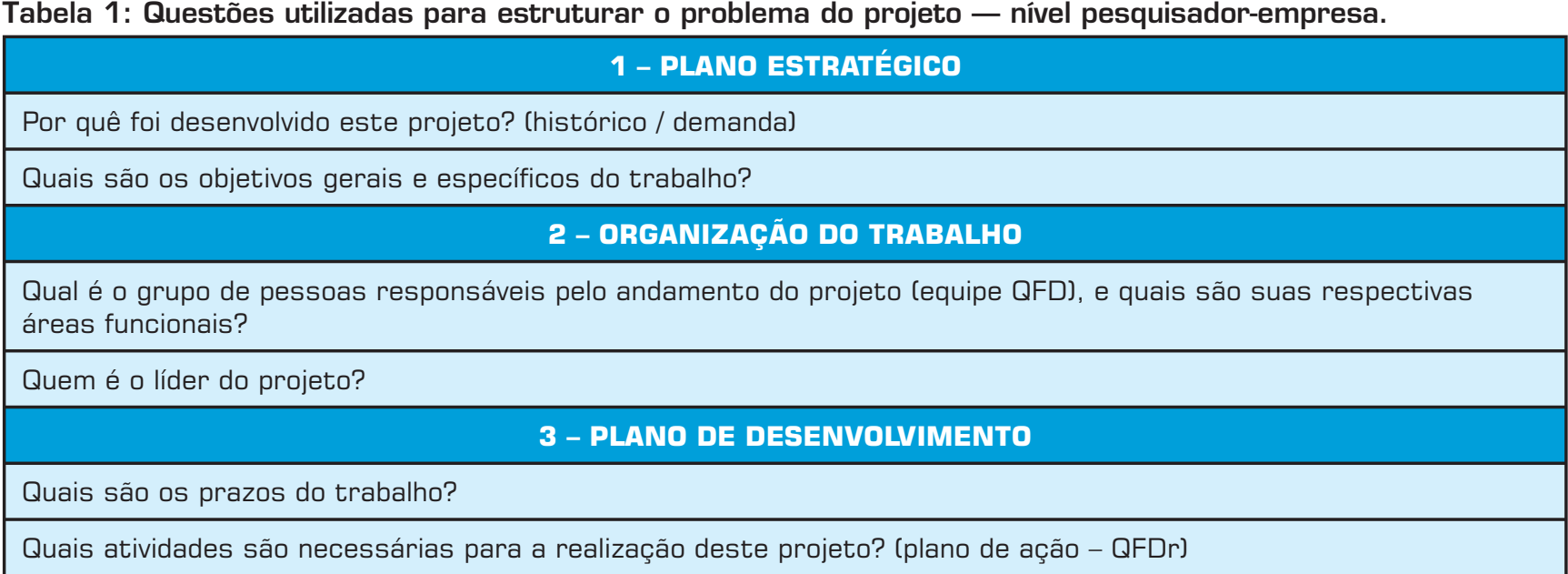


diário era feito por meio de anotações manuais que, posteriormente, eram transcritas para um arquivo eletrônico, ou eram redigidas diretamente nesse arquivo. $\mathrm{O}$ diário segue a estrutura abaixo:

- Semana de trabalho / dias da visita;

- Atividades propostas para esta visita;

- Atividades realizadas;
- Análise dos trabalhos realizados;

- Atividades propostas para próxima visita.

\section{APLICAC̣̃̃O E RESULTADO DO PROJETO}

Este trabalho foi desenvolvido por uma empresa produtora de cal de um dos maiores grupos privados do país. Neste

Tabela 2: Questões utilizadas para estruturar o problema do projeto — nível pesquisador-pesquisador.

\begin{tabular}{|l|}
\hline \multicolumn{1}{|c|}{1 - PAPÉIS } \\
\hline Quem são os clientes? E quais são as suas expectativas? \\
\hline Quem é o possuidor do problema? \\
\hline Quem é o decisor que pode alterar os arranjos do sistema social e decidir sobre a alocação de recursos do sistema? \\
\hline \multicolumn{2}{|c|}{ - SISTEMA CONTEÚDO-PROBLEMA } \\
\hline Qual a versão/percepção da natureza do problema que o cliente, possuidor e decisor possuem? \\
\hline Quais são as razões para que cada um deles enxergue o problema como problemático? \\
\hline Quais são as restrições externas/ambientais do sistema conteúdo-problema? \\
\hline \multicolumn{3}{|c|}{ - SISTEMA DE RESOLUÇÃO-PROBLEMA } \\
\hline Quais são as outras pessoas envolvidas no problema (não fazem parte do grupo formado para o trabalho]? \\
\hline Quais são os recursos (tempo, dinheiro, recursos físicos, etc.) do sistema? \\
\hline Quais são as restrições conhecidas e possíveis do sistema? \\
\hline Quando o grupo envolvido saberá que o problema está resolvido? \\
\hline
\end{tabular}

Tabela 3: Etapas do procedimento operacional realizado em cada seção de trabalho no dia-a-dia da empresa.

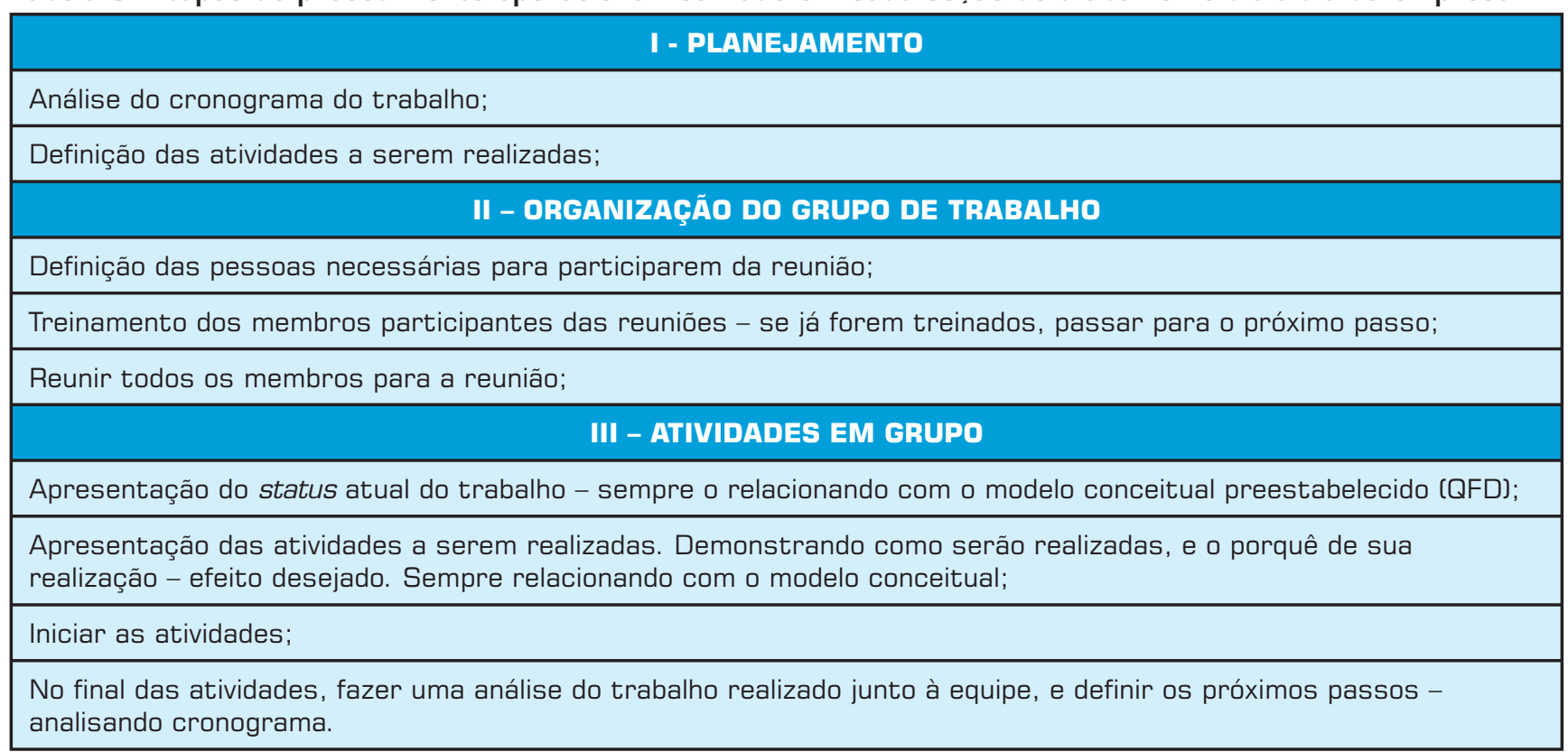


projeto, o produto desenvolvido foi um tipo de cal hidratada $(\mathrm{CH})$, que é especificada por sua composição química, estrutura física e características físico-químicas. Desenvolveu-se o projeto em função do desejo de um cliente único para que a densidade do produto $(\mathrm{CH})$ fosse aumentada, sem prejuízo das outras características. Portanto, neste projeto, o QFD foi aplicado para auxiliar a garantia da qualidade de um produto durante seu reprojeto.

O objetivo deste projeto foi "adequar o produto cal hidratada especial $(\mathrm{CH})$ à qualidade exigida pelo cliente", que foi desdobrado em seis objetivos específicos: 1- traduzir as verdadeiras necessidades do cliente para o processo produtivo; 2 - adequar às necessidades do cliente as características de qualidade do produto final, das matérias-primas, dos produtos intermediários, dos processos e parâmetros de controle; 3- maximizar o rendimento do processo; 4- levantar as possíveis alterações no processo produtivo, equipamentos e parâmetros de controle, que poderiam, principalmente, melhorar as características do produto final aos olhos do cliente; 5- alterar características do processo produtivo em função das informações obtidas; e 6- avaliar o possível impacto que tais alterações poderiam causar nos índices de controle do processo, durante o reprojeto do produto.

Os dois primeiros objetivos específicos da empresa relacionam-se mais com as exigências do cliente externo; enquanto os quatro últimos, mais com a qualidade exigida interna. $\mathrm{O}$ cliente externo é aquele que comprará o produto, o interno é aquele que fabricará o produto, no caso, a empresa. Assim, nesse projeto, houve uma clara distinção entre cliente externo e interno.

\section{Aplicação do Método QFD}

Em função dos objetivos 1 e 2 do projeto, seria necessário um modelo conceitual mais elaborado, que incluísse a matriz da qualidade e as tabelas de parâmetros de controle, processos e matérias-primas, de acordo com o Guia de Intervenção - situação três (Figura 2). Para que os objetivos 3 ao 6 fossem alcançados, seria preciso um

\section{/ odelo conceitual utilizado foi dividido em dois desdobramentos: desdobramento}

\section{da qualidade positiva e desdobramento da tecnologia do processo de fabricação.}

outro desdobramento, o desdobramento da tecnologia do processo de fabricação, que incluísse matrizes formadas por tabelas de parâmetros de controle, processos, equipamentos, índices de controle do processo e possíveis alterações nas características do processo de fabricação. Contudo o modelo conceitual utilizado foi dividido em dois desdobramentos, que foram: desdobramento da qualidade positiva (DQ) e desdobramento da tecnologia do processo de fabricação (DT). Vale ressaltar que outros desdobramentos do QFD, além do da qualidade positiva, não foram tratados no guia de intervenção. Realizou-se o DT em função de um gargalo tecnológico identificado no início do projeto, o aumento da densidade da $\mathrm{CH}$ sem o prejuízo das outras características, que era o desejo do cliente. O modelo conceitual utilizado nesse trabalho está apresentado na Figura 4.

Figura 3: Grupo principal vs. Grupos de trabalhos diários.

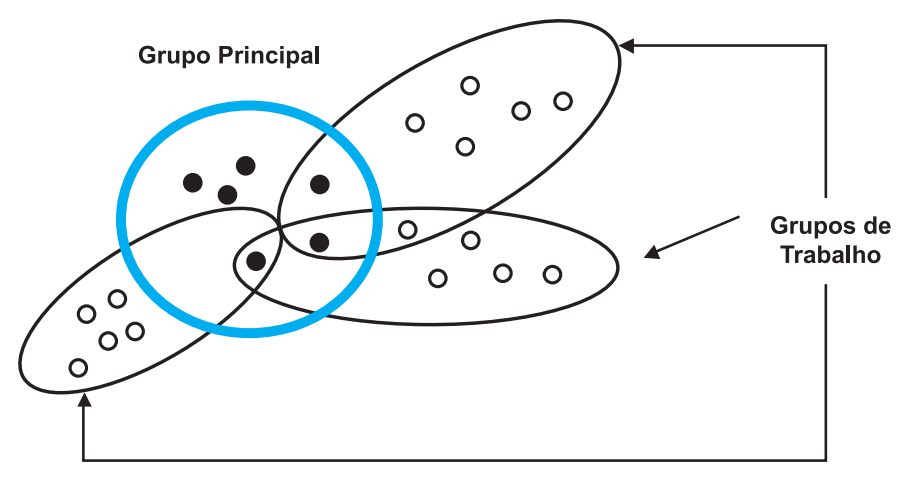


Como relatado anteriormente, nesse projeto houve uma clara distinção entre cliente externo e interno. O cliente externo é aquele que comprará o produto, e suas exigências estão no mundo da qualidade positiva, na tabela das qualidades exigidas. Enquanto, o interno é aquele que fabricará o produto, no caso a empresa, e suas exigências estão no mundo da tecnologia, na tabela de índice de controle (IC IDP índice de desempenho do processo). Estes últimos são: produtividade, disponibilidade e rendimento. de controle também poderá(ão) ser alterado(s), o que poderá afetar as CQPF. Estes procedimentos estão representados nas Figuras 5 (a) e 5 (b).

Para que algum parâmetro de controle fosse alterado durante o reprojeto do produto, tanto objetivando alteração(ões) de CQPF e/ou por conseqüência IC, e vice-versa, é necessário que alguma(s) característica(s) de equipamento(s) seja(m) alterada(s), o que partiria de ações originadas do mundo da tecnologia do processo de fabricação. A Figura 5(c) representa a relação de efeito-causa desse procedimento de análise.

Esses procedimentos apresentados forneceram uma análise de vaivém entre os dois mundos durante o reprojeto do produto, o que robusteceu o modelo conceitual e também aumentou a troca de conhecimento entre as pessoas do grupo de desenvolvimento.

O formato desse modelo permitiu ao trabalho as seguintes análises. Alterando um parâmetro de controle com a finalidade de melhorar uma(s) característica(s) de qualidade do produto final (DQ), será necessário alterar alguma(s) característica(s) dos equipamentos do processo, o que poderá afetar os índices de controle de produção (DT). Por conseqüência, se for importante alterar alguma característica de equipamento(s), durante o reprojeto do produto, com a finalidade de melhorar algum IC (IDP), algum(ns) parâmetro(s)
Preenchimento das matrizes deste projeto - Foram utilizadas duas formas de preenchimento das matrizes. Para definição das correlações entre as tabelas do modelo conceitual, utilizou-se o critério mostrado na Tabela 4. As cores atribuídas aos valores das correlações propiciaram visibilidade às matrizes. A proporcionalidade como apresentada nessa tabela foi utilizada para o preenchimento das matrizes auxiliares, CQPF $\times$ CQPF e PCP $\times$ PCP.

Outra notação utilizada foi a representação de como os

Figura 4: Modelo conceitual.

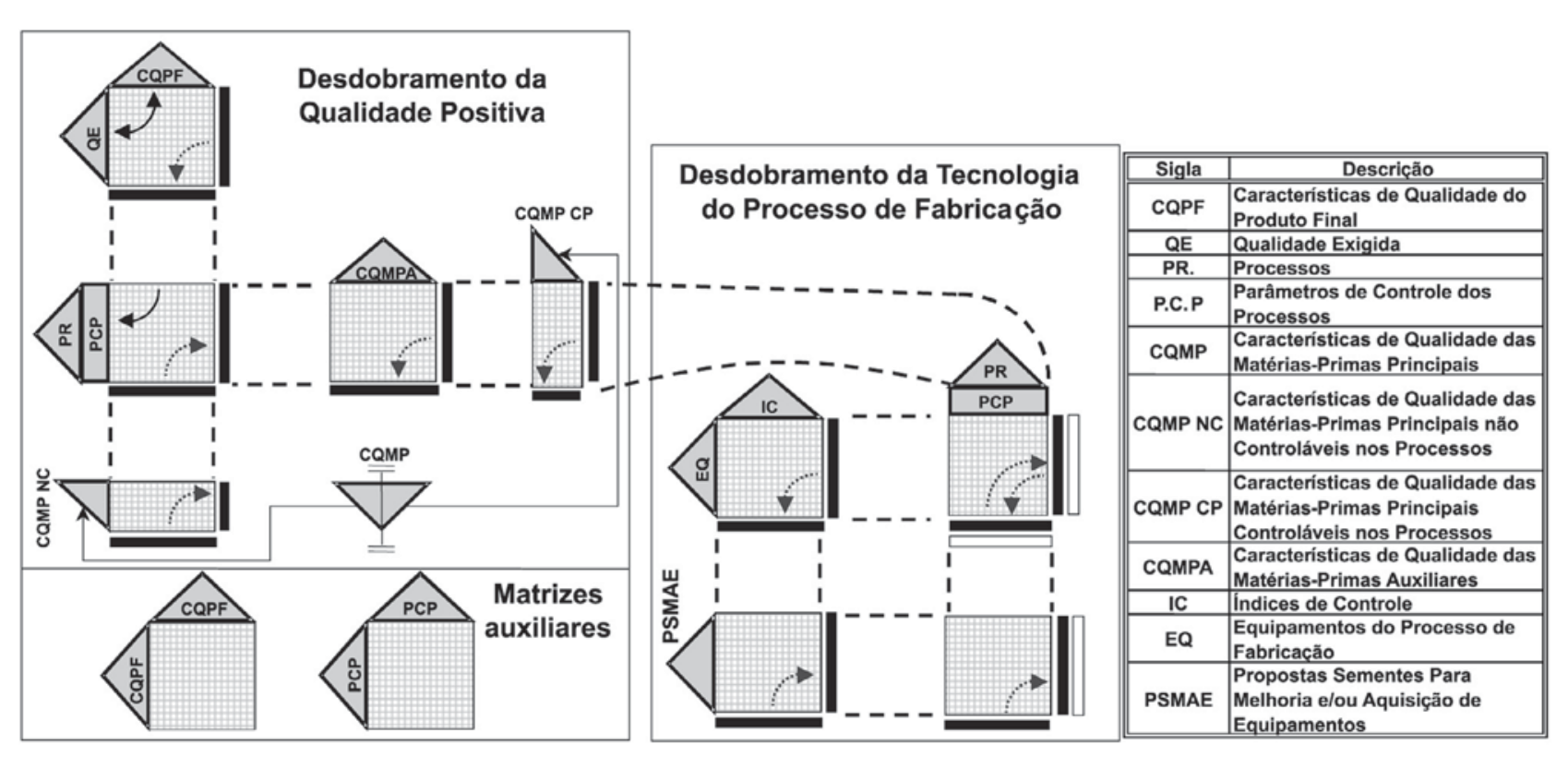


valores das especificações das QE, CQPF e CQMP deveriam se comportar em função das necessidades da empresa. Esta notação está representada na Tabela 5. Foi necessário utilizar o critério apresentado em função da complexidade desta indústria de materiais que possui muitas variáveis interdependentes, e seus comportamentos não estavam claros para todos os participantes do trabalho. Isto possibilitou uma melhor compreensão dessas variáveis e das suas relações

Figura 5: (a) Representação de um possivel efeito no IC causado pela alteração de algum(ns] parâmetro[s] de controle em função da necessidade de alterar alguma(s) característica(s) de qualidade do produto final. (b) Representação de um possivel efeito nas CQPF causado pela alteração de algum(ns) parâmetro[s] de controle de equipamento[s] em função da necessidade de alterar algum(ns) IC. (c) Representação dos possiveis efeitos causados por ações de mudanças em características de equipamentos do processo produtivo durante o reprojeto do produto.

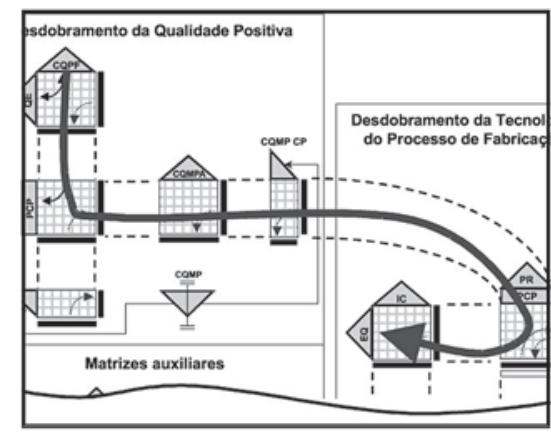

(a)

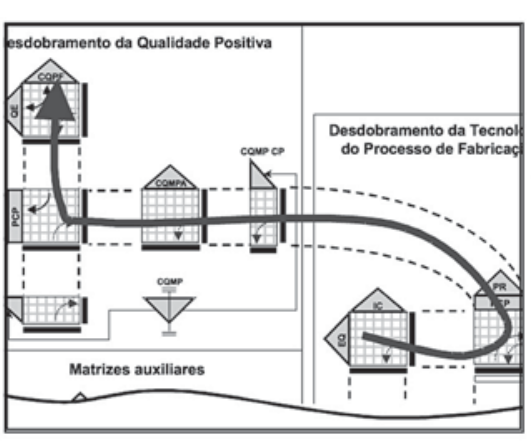

(b)

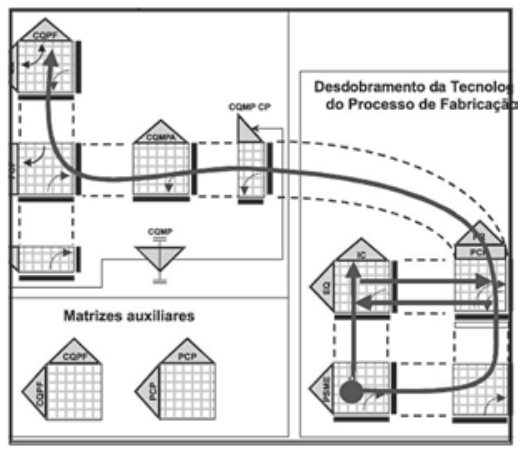

(c)

Tabela 4: Critério utilizado para o preenchimento das matrizes

\begin{tabular}{|c|c|c|c|}
\hline CORRELAÇÃO & DESCRIÇÃO & VALOR & COR DO No \\
\hline Forte & COM CERTEZA os itens serão diretamente impactados entre si. & 9 & Vermelho \\
\hline Média & PROVAVELMENTE os itens estudados serão impactados entre si. & 3 & Verde \\
\hline Fraca & HÁ SUSPEITA de que os itens serão impactados entre si. & 1 & Azul \\
\hline Nula & Não há correlação entre os itens. & - & \\
\hline Proporcionalidade & & & Cor da cédula \\
\hline $\begin{array}{l}\text { Fortemente } \\
\text { proporcional }\end{array}$ & Se um item altera, o outro alterará na mesma proporção. & 9 & Branca \\
\hline Proporcional & $\begin{array}{l}\text { Se um item altera, o outro poderá alterar simultaneamente na } \\
\text { mesma direção, dependendo das condições atuais ou de outros } \\
\text { fatores. }\end{array}$ & 3 & Branca \\
\hline $\begin{array}{l}\text { Fortemente } \\
\text { inversamente } \\
\text { proporcional }\end{array}$ & Se um item altera, o outro alterará na proporção inversa. & 9 & Verde-claro \\
\hline $\begin{array}{l}\text { Inversamente } \\
\text { proporcional }\end{array}$ & $\begin{array}{l}\text { Se um item altera, o outro poderá alterar simultaneamente na } \\
\text { direção oposta, dependendo das condições atuais ou de outros } \\
\text { fatores. }\end{array}$ & 3 & Verde-claro \\
\hline
\end{tabular}


de causa-efeito, explicitando os conhecimentos tácitos dos indivíduos.

As matrizes foram preenchidas pelos integrantes do grupo de desenvolvimento e pelos trabalhadores da fábrica em sessões de trabalhos periódicas. Participaram dessas reuniões apenas as pessoas "chaves", para que os resultados desejados fossem alcançados. Os valores definidos nas correlações e proporcionalidades foram obtidos pelo consenso resultante das discussões dos participantes. Segundo Cheng (2003), em relação ao fim metodológico, o método QFD tem como fim obter consenso que leva a ações acordadas em projetos de desenvolvimento ao facilitar melhor entendimento e aprendizagem dos participantes, além da acumulação de conhecimento para a organização. Esse fim é alcançado na medida em que os indivíduos são trazidos de diferentes bases de formação num projeto de QFD, para revelar e debater suas diferentes lógicas de estruturação e raciocínio. Conforme as diferenças individuais e suas áreas de formação e atuação, acredita-se que a lógica de estruturação e raciocínio pode variar bastante no que diz respeito ao por quê, o que e como a informação pode ser coletada, processada e distribuída, ou o trabalho pode ser estruturado, alocado e executado. Ao revelar e debater sobre as similaridade e diferenças, espera-se que consenso e ações acordadas possam ser implementadas. Assim, a correlação nas matrizes, bem como a elaboração das tabelas e modelo conceitual, foram os instrumentos (visíveis e hierárquicos) para organizar, estruturar, priorizar e efetuar o benchmarking de dados objetivamente, de forma a atingir os objetivos do tranbalho e que, em paralelo, possibilitou a aprendizagem individual e coletiva e acumulação de conhecimento.

A segunda forma de preenchimento das matrizes baseou-se em algumas análises comparativas entre resultados obtidos da aplicação da técnica planejamento

Tabela 5: Simbologia utilizada para representar melhor o comportamento das QE, CQPF e CQMP.

\begin{tabular}{|l|c|}
\hline Quanto maior melhor & $\uparrow$ \\
\hline Quanto menor melhor & $\downarrow$ \\
\hline
\end{tabular}

\begin{tabular}{|l|c|}
\hline Quanto maior melhor, mas possui um valor-limite superior & $\bar{\uparrow}$ \\
\hline Quanto menor melhor, mas possui um valor-limite inferior & $\underline{\downarrow}$ \\
\hline
\end{tabular}

Valor especificado em um limite superior e inferior

Figura 6: Matriz QE x CQPF. 12 linhas / 24 colunas.

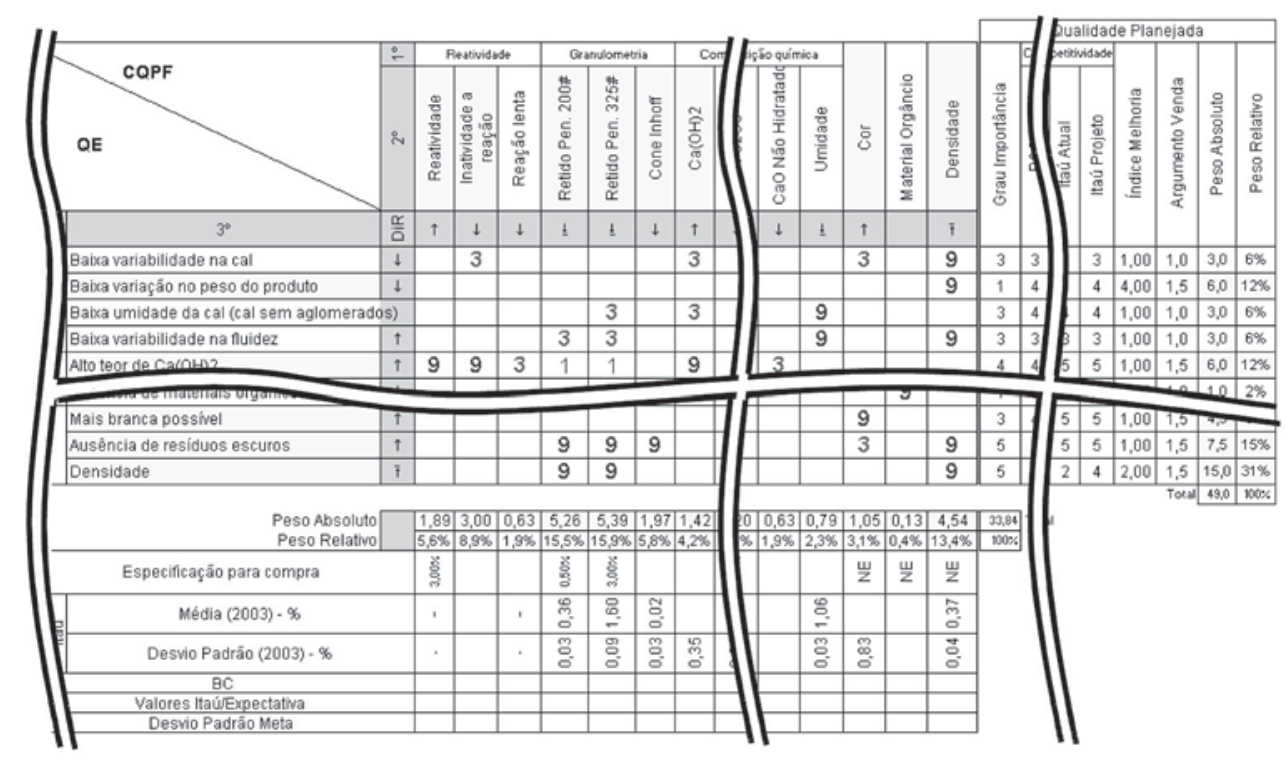


e análise de experimentos e no consenso da equipe. As matrizes $\mathrm{QE} \times \mathrm{CQPF}, \mathrm{CQPF} \times \mathrm{Pr} . \mathrm{PCP}, \mathrm{IC} \times \mathrm{EQ}$ e EQ $\times$ Pr. PCP estão representadas nas Figuras 6, 7, 8 e 9. Com os pesos relativos obtidos para cada item das matrizes, foram construídos Gráficos de Pareto, como o mostrado na Figura 10.

\section{Planejamento e análise de experimentos - uma técnica auxiliar ao QFD}

Objetivando identificar os possíveis fatores que afetam uma característica de qualidade do produto final, densidade, e definir as propostas sementes para melhoria e/ou aquisição de equipamento, foram realizados experimentos em laboratório. O primeiro objetivo relaciona-se à definição de correlações no mundo da qualidade; enquanto, o segundo relaciona-se à definição de ações sobre os equipamentos no mundo da tecnologia (ver Figura 4). Vale ressaltar que não foi tratado no guia de intervenção (Figura 2) se o uso de técnicas estatísticas é recomendado, e qual seria a mais apropriada para definição de correlações das matrizes e obtenção de outras informações (além da especificação de valores). Foram realizados três experimentos e cinco análises dos dados. Neste relato, serão apresentadas partes do terceiro experimento e duas de suas análises.

\section{Definição dos fatores e objetivos do experimento}

Pode-se dizer que o grupo de trabalho possuía diferentes hipóteses sobre os possíveis fatores que afetariam a característica de qualidade densidade da Cal Hidratada $(\mathrm{CH})$. Análises dos resultados obtidos das Matrizes CQPF $\times$ Pr.PCP, Pr.PCP $\times$ CQMPCP e CQPF $\times$ CQMPNC forneceram informações relevantes para escolha dos fatores de análise. Os

\section{$\square$ lanejamento e análise de experimentos como auxiliar ao QFD levantou informações importantes, utilizadas na definição das ações.}

parâmetros de controle que mais afetariam a densidade da $\mathrm{CH}$, correlação 9, e menos afetariam outras características de qualidade do produto, peso relativo $6 \%$, seriam dois: tempo de residência na hidratação (tempo de hidratação) e tempo de maturação (ver Figura 11). Esses parâmetros não eram controlados pela empresa até o momento, o que gerou maior interesse por suas análises. Contudo, decidiu-se analisar se apresentam efeitos estatisticamente significativos na densidade da $\mathrm{CH}$.

Ainda, esses parâmetros seriam influenciados pelas características de qualidade das matérias-primas, cal virgem, controladas no processo (ver Figura 12-a); e, uma

Figura 7: Matriz CQPF x Pr.PCP. 16 linhas / 24 colunas.

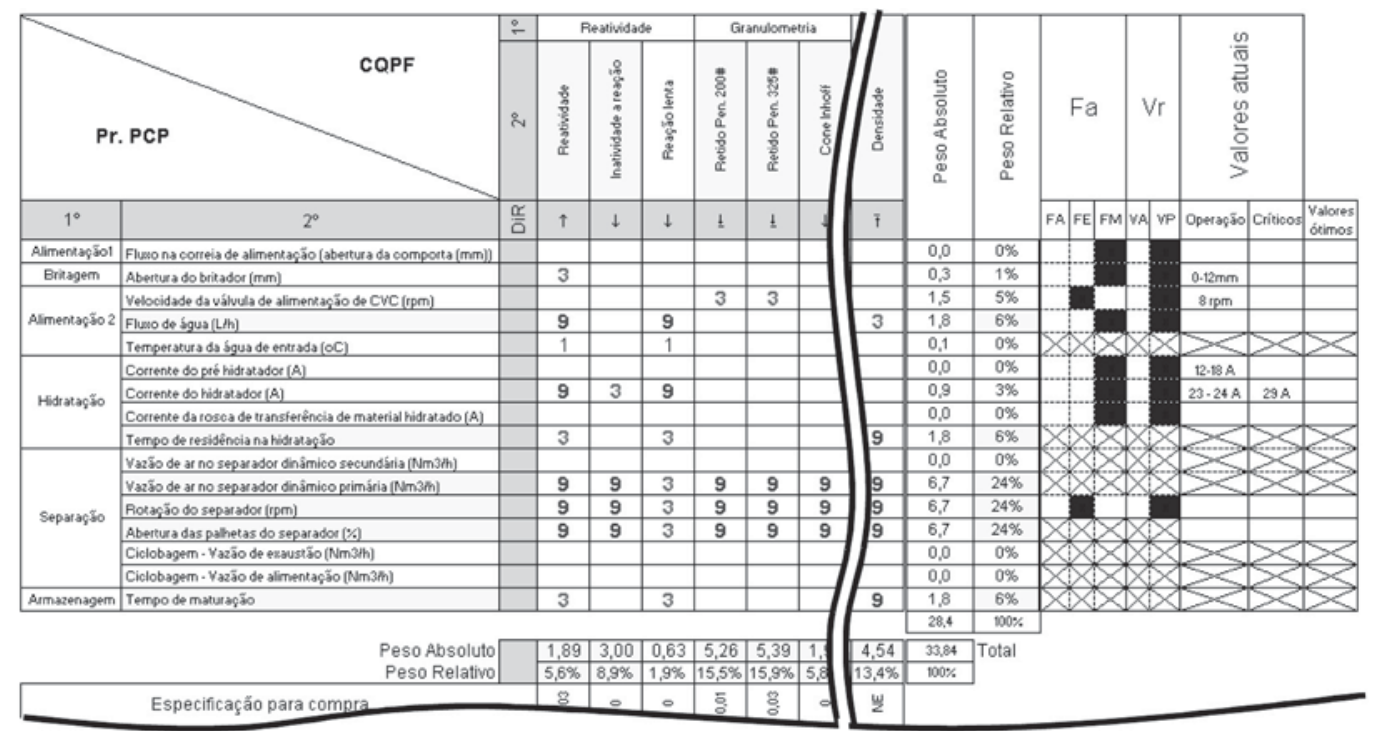


Figura 8: Matriz IC x EQ. 24 linhas / 3 colunas.

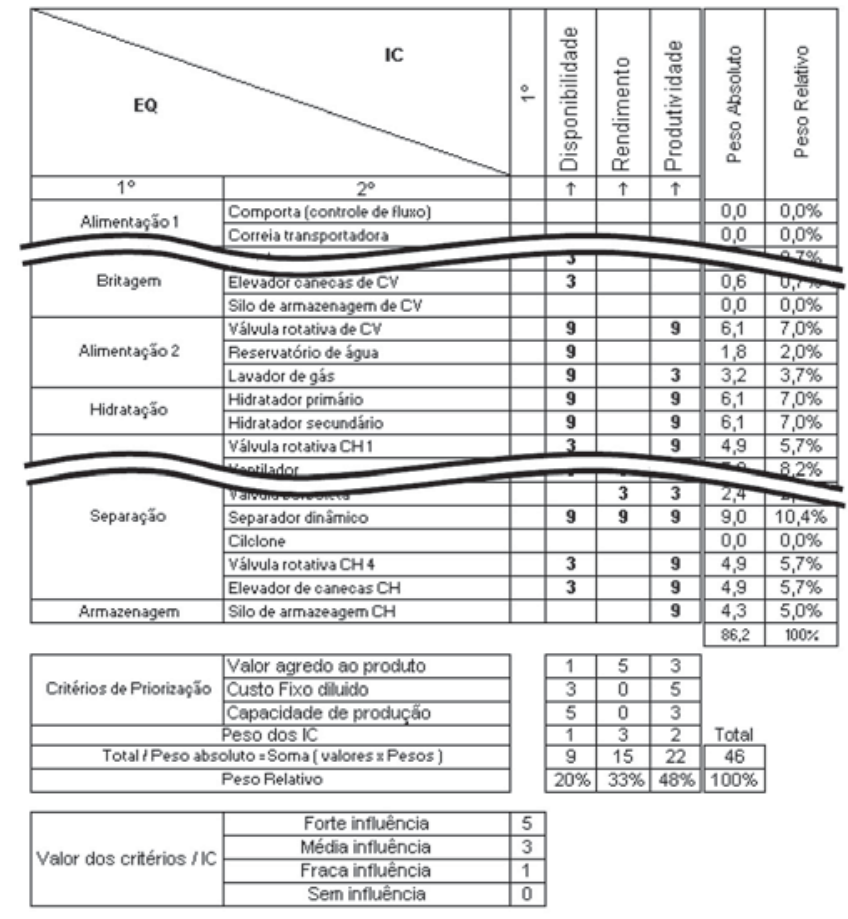

Figura 9: Matriz EQ x Pr. PCP. 24 linhas / 16 colunas.

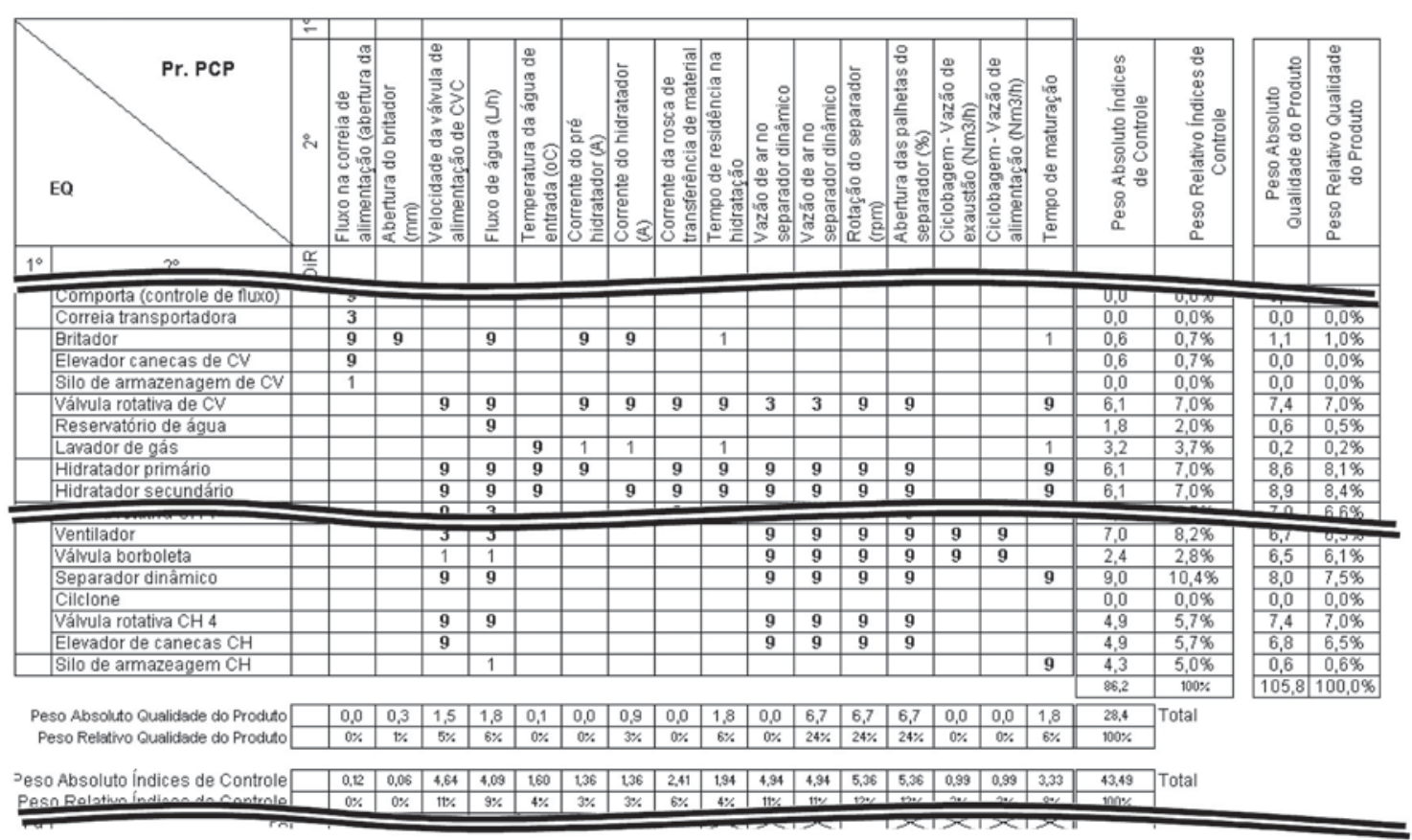


característica de qualidade da matéria-prima não controlada influenciaria diretamente a densidade (ver Figura 12-b). Assim, a equipe suspeitou que cales produzidas sob diferentes condições seriam alteradas diferentemente pelos parâmetros de controle da hidratação e, por conseqüência, causariam efeitos diferentes na densidade. Essas condições eram caracterizadas por: características do calcário (matéria-prima da cal), características dos fornos e combustíveis (matriz energética) utilizados.

A equipe não desejava desenvolver uma nova matéria-

Figura 10: Gráfico de Pareto da priorização dos Pr.PCP em função dos pesos das CQPF obtidas no mundo da qualidade positiva.

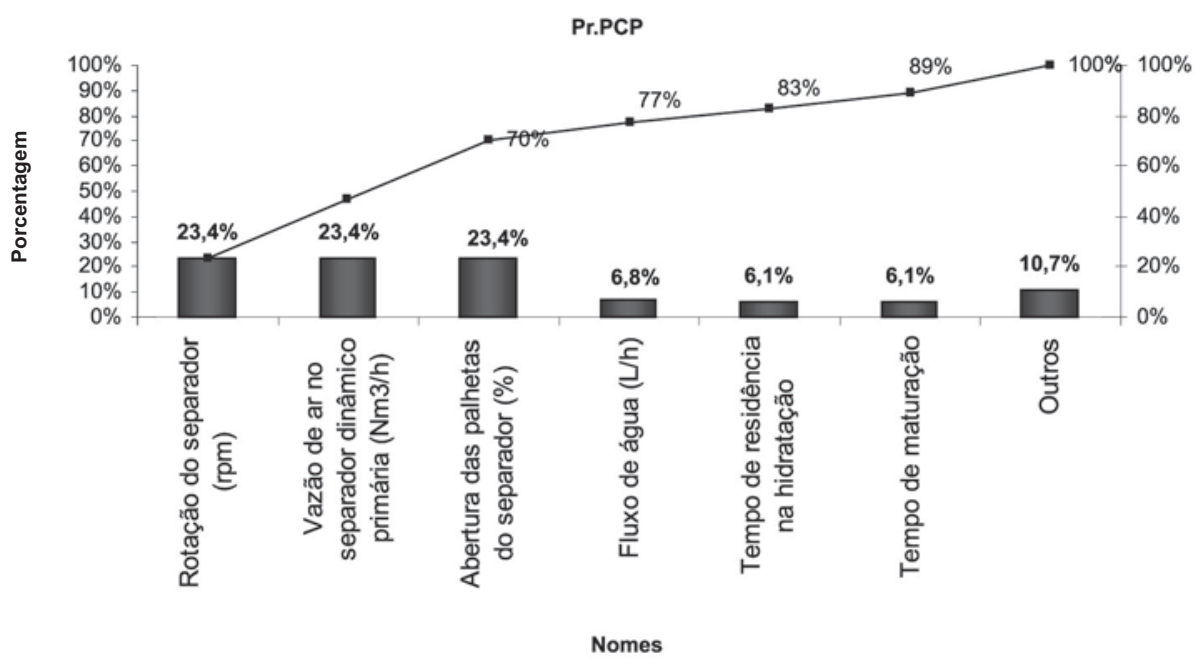

Figura 11: Resultados da matriz CQPF $\times$ Pr.PCP.

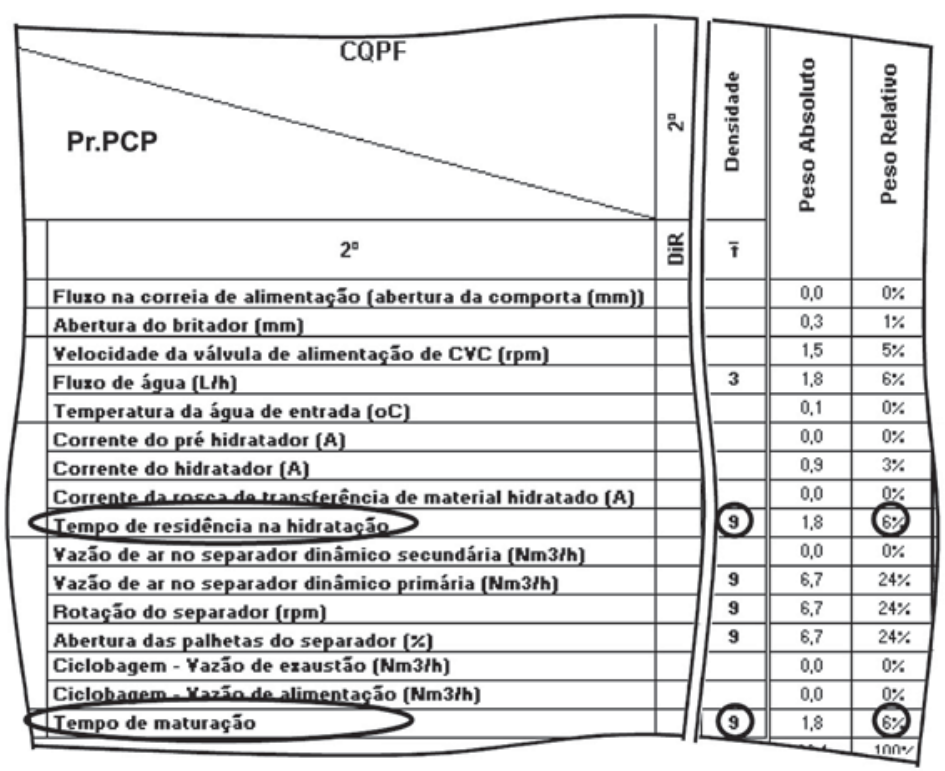


prima, e sim escolhê-la em função das que já eram produzidas. No entanto, decidiu-se analisar também se diferentes tipos de cales afetariam a densidade da $\mathrm{CH}$. Essa análise seria realizada como um todo, em função das necessidades da equipe e disponibilidade de recursos; isto é, não seriam analisadas as características de qualidade das matérias-primas, e sim o conjunto delas como um todo, que seria diferenciado pelo tipo de cal. Contudo, definiram-se como objetivos do experimento: a - analisar se o tempo de hidratação $(\mathrm{TH})$ afeta a densidade; $b$ - analisar se o tempo de maturação (TM) afeta a densidade; e c - analisar se diferentes tipos de cales afetam a densidade. Para os fatores TM e TH foram analisados dois níveis, para três diferentes tipos de cales. Os fatores e seus níveis utilizados estão mostrados na Tabela 6.

O experimento escolhido foi o Fatorial Sem Réplicas. Não se realizaram réplicas em função da restrição de recursos. Os resultados obtidos estão mostrados na Tabela 7. Quanto à análise dos dados, realizaram-se duas análises utilizando-se o software Minitab® (Ver Figura 13).

ANÁLISE 1 - Como não houve réplicas, foi desprezada

Figura 12: (a) - Resultados da matriz Pr.PCP $\times$ CQMPCP. (b) Resultados da matriz CQMP $\times$ CQMPNC.

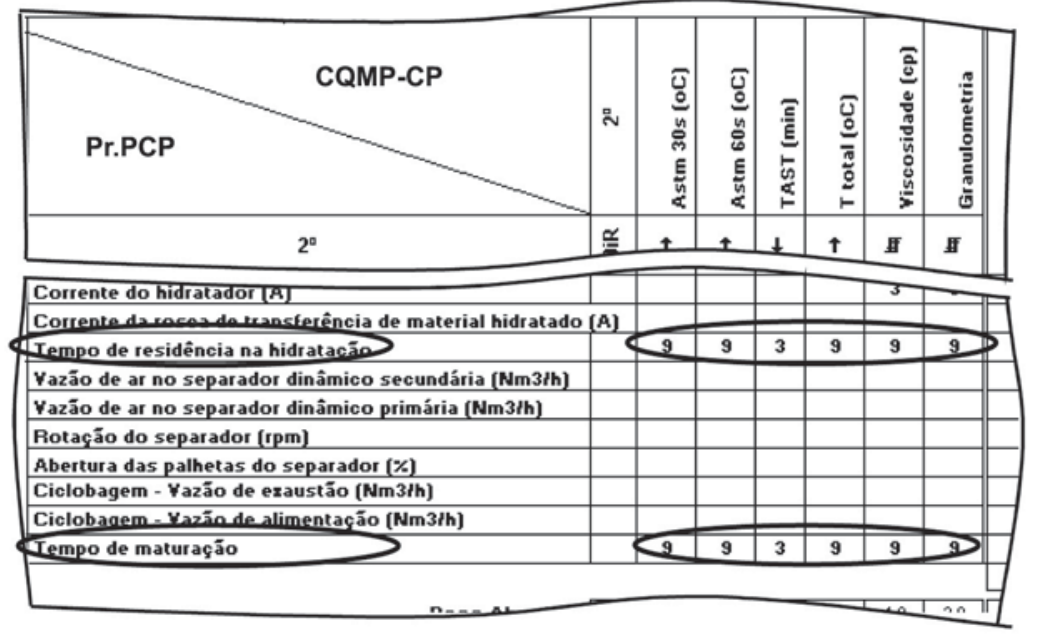

(a)

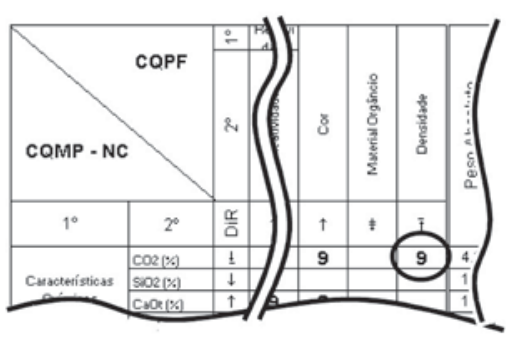

(b)

Tabela 6: Fatores e níveis de análise.

\begin{tabular}{|l|l|}
\hline \multicolumn{2}{|c|}{ FATOR 1 - TIPO CAL } \\
\hline \multicolumn{2}{|c|}{} \\
\hline Nível 1 & 705 F2 (Azbe) Lenha \\
\hline Nível 2 & 705 F5 (Maerz) Coque \\
\hline Nível 3 & 725 F3 (Maerz) Coque \\
\hline
\end{tabular}

\begin{tabular}{|l|l|l|}
\hline \multicolumn{3}{|c|}{ FATOR 2 - TEMPO DE HIDRATAÇÃO } \\
\hline & & Valor (mim) \\
\hline nível 1 & $15 \mathrm{~min}$ & 15 \\
\hline nível 2 & $60 \mathrm{~min}$ & 60 \\
\hline
\end{tabular}

\begin{tabular}{|l|l|l|}
\hline \multicolumn{3}{|c|}{ FATOR 3 - TEMPO DE MATURAÇÃO } \\
\hline & & Valor (horas) \\
\hline Nível 1 & sem maturação & 0 \\
\hline Nível 2 & com maturação & 48 \\
\hline
\end{tabular}


a interação entre os três fatores, a qual foi tratada como fonte de erro, com dois graus de liberdade. Realizou-se uma análise da variância dos resultados, conforme mostra a Figura 13, para 95\% de confiança. As suposições do modelo utilizado para análise (Modelo de Efeitos Fixos) foram verificadas e aceitas. Para maiores informações ver Melo Filho (2005).

Os valores-p do fator 1 e das interações entre os fatores 1 x 2,2 x 3 e 1 x 3 são maiores que 0,05. Assim, não influenciariam na densidade da cal. Já os valores-p para os fatores 2 (tempo de hidratação) e 3 (tempo de maturação) são menores que 0,05 . Assim, influenciariam na densidade da cal. $O$ gráfico dos efeitos principais, Figura 14, como verificado na análise de variância 1, mostra que ambos os fatores 2 e 3 influenciam na densidade, mas o tempo de maturação influenciaria mais que o de hidratação, para os níveis analisados.

Como, estatisticamente verificado por meio da análise de variância 1, o fator tipo de cal e suas interações com os outros fatores não influenciam na densidade, decidiu-se realizar outra análise desprezando o efeito desse fator, considerando que haveria três réplicas dos experimentos.

ANÁLISE 2 - Em função da não utilização do efeito do Tipo Cal, utilizou-se outro tipo de análise do experimento, que foi a Fatorial $-2^{2}$ com três réplicas. Realizou-se uma análise da variância dos resultados, mostrada na Figura 15.

Os valores-p dos dois fatores são menores que 0,05 , assim, influenciariam na densidade do produto. Mas o valor-p da interação é maior que 0,05 , portanto, não influenciaria

Tabela 7: Resultados do experimento.

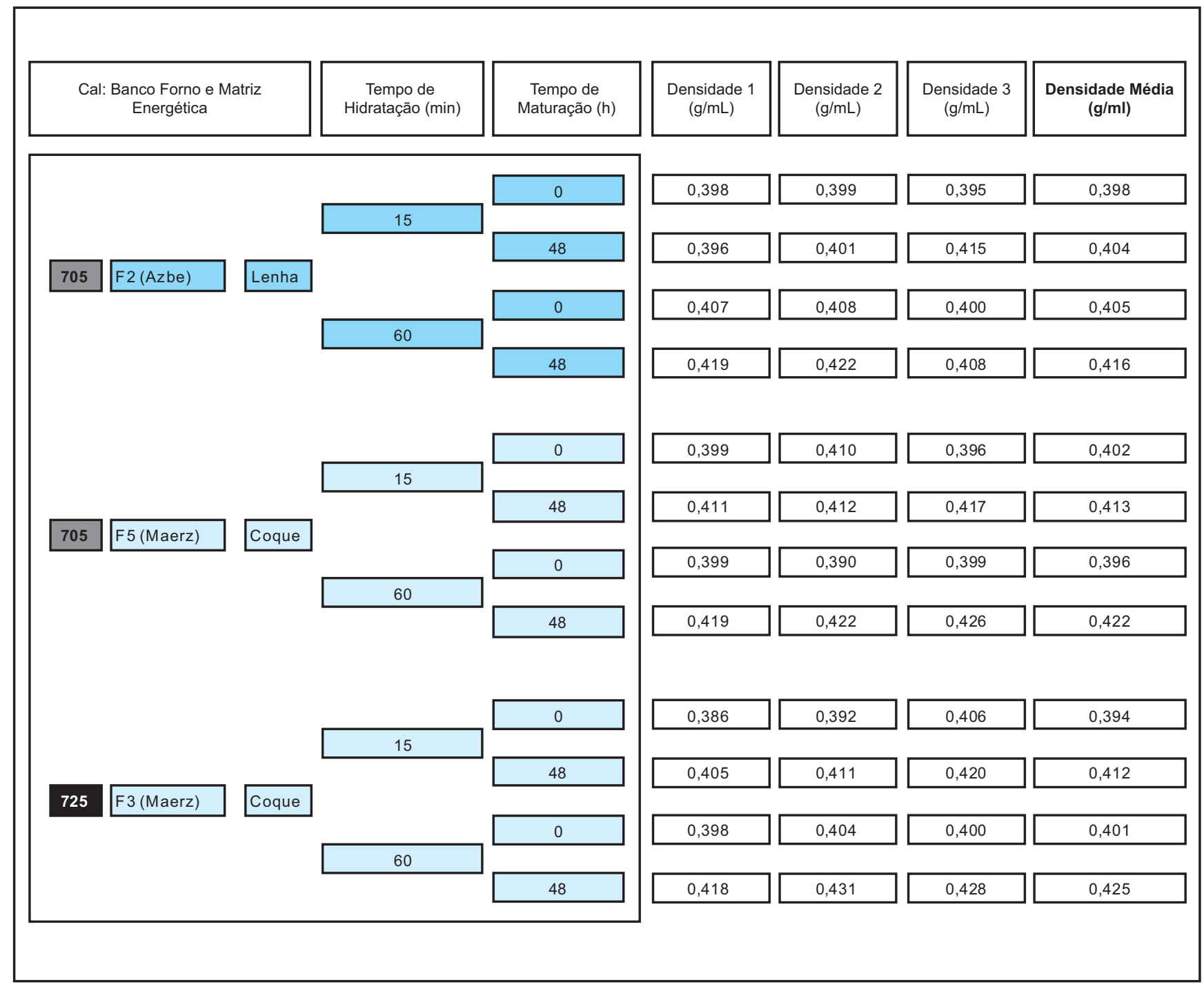


na variável resposta. Essas foram as mesmas conclusões obtidas anteriormente na análise 1. Nessa análise 2, o efeito atribuído ao tempo de maturação foi maior que o dobro do atribuído ao tempo de hidratação para os níveis avaliados. A análise do gráfico dos efeitos principais, Figura 16, reforça a interpretação realizada sobre a análise de variância. Mesmo não sendo as interações paralelas, como apresentado pela Figura 17(a), estatisticamente

Figura 13: Análise de variância dos resultados / Análise 1.

\begin{tabular}{|c|c|c|c|c|c|c|}
\hline Source & $\mathrm{DF}$ & Seq SS & Adj SS & Adj MS & $\mathrm{F}$ & $\mathrm{P}$ \\
\hline Tipo cal & 2 & 0,0000152 & 0,0000152 & 0,0000076 & 1,00 & 0,500 \\
\hline T. Hidra & 1 & 0,0001470 & 0,0001470 & 0,0001470 & 19,38 & 0,048 \\
\hline T. Matur & 1 & 0,0007680 & 0,0007680 & 0,0007680 & 101,27 & 0,010 \\
\hline Tipo cal*T. Hidra & 2 & 0,0000455 & 0,0000455 & 0,0000227 & 3,00 & 0,250 \\
\hline Tipo cal*T. Matur & 2 & 0,0000875 & 0,0000875 & 0,0000437 & 5,77 & 0,148 \\
\hline T. Hidra*T. Matur & 1 & 0,0000563 & 0,0000563 & 0,0000563 & 7,43 & 0,112 \\
\hline Error & 2 & 0,0000152 & 0,0000152 & 0,0000076 & & \\
\hline Total & 11 & 0,0011347 & & & & \\
\hline
\end{tabular}

Figura 14: Efeitos principais / Análise 1.

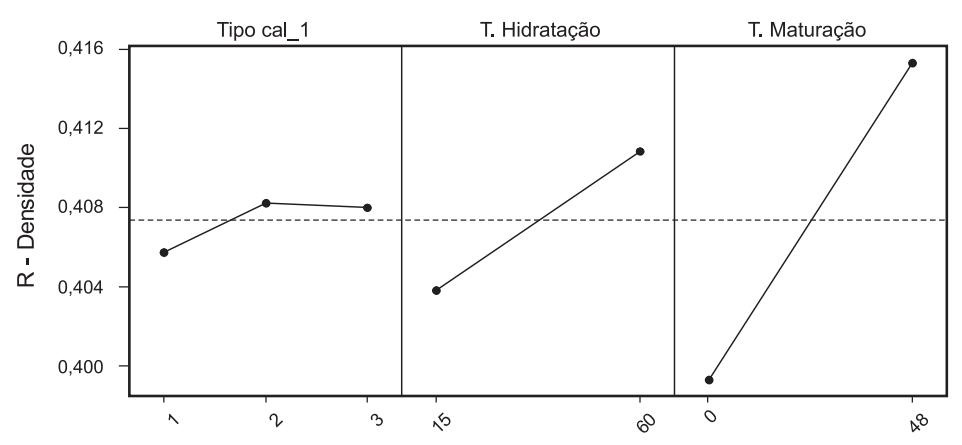

Figura 15: Análise de variância dos resultados / Análise 2.

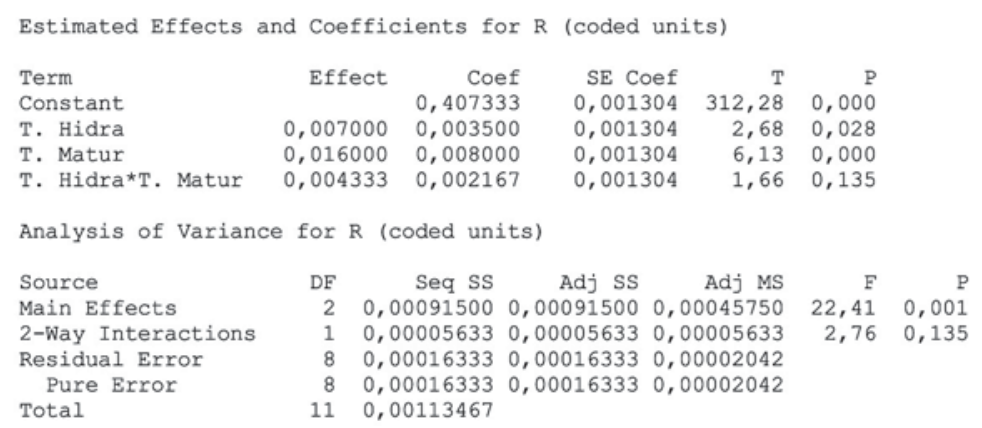


pode-se considerar que não há interação entre os fatores, em função da análise 2 de variância. A densidade foi maior quando o tempo de hidratação foi de 60 min e o tempo de maturação de 48 horas, assim como na análise 1. A Figura 17(b) reforça esta análise. Como quanto maior a densidade melhor, as faixas de valores a serem analisadas em outros experimentos seriam para os valores maiores de tempo de hidratação e maturação.

A Figura 18 mostra uma representação esquemática de onde o planejamento de experimentos se encaixaria no modelo conceitual. Durante as reuniões realizadas antes dos experimentos, definiu-se em consenso que, com certeza, os parâmetros de controle tempo de hidratação e maturação afetariam a densidade da cal hidratada.
Os resultados dos experimentos demonstraram que é estatisticamente significativo que os fatores afetariam a densidade. Essas correlações estão representadas na Figura 18, na matriz Pr.PCP x CQPF, e as colunas à direita representam os níveis dos fatores analisados. Essas conclusões dos experimentos foram obtidas pelas análises de variância realizadas, e os valores obtidos que alimentaram os resultados das correlações do QFD estão ligados por uma seta às conclusões. Lembrando que, quando o valor-p do fator é menor que 0,05 , esse afetaria a densidade (variável resposta).

Em função das conclusões obtidas dos experimentos e das análises realizadas nas matrizes, foram definidas as Propostas Sementes para Melhoria e/ou Aquisição de Equipamentos (PSMAE), e construíram-se as matrizes PSMAE $\times$

Figura 16: Efeitos principais / Análise 2.

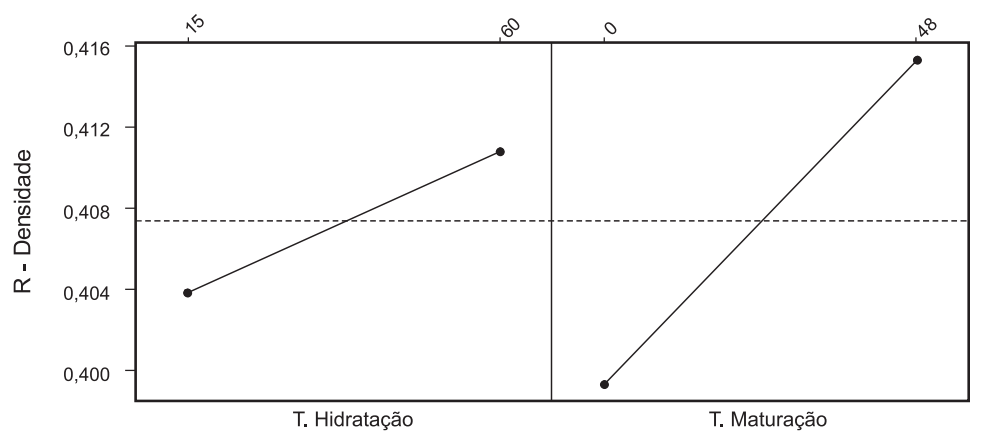

(a)

(b)

Figura 17: (a) Interação entre os fatores; (b) Cubo / Análise 2.
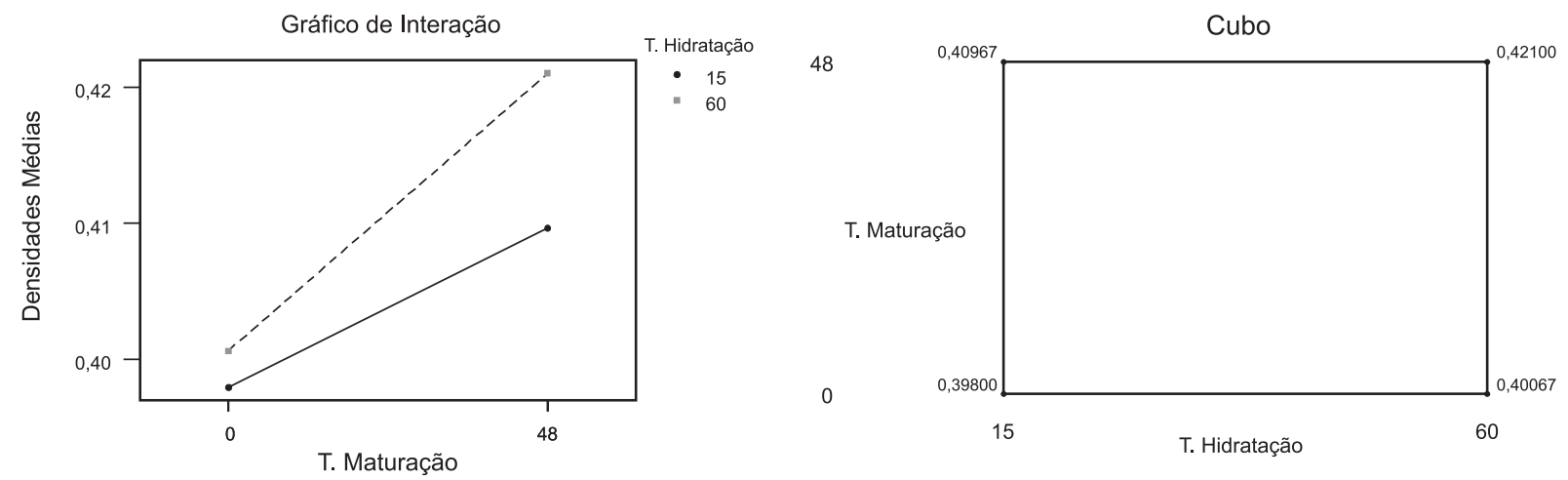
IC (ver Figura 19) e PSMAE $\times$ PCP, pertencentes ao modelo conceitual do desdobramento da tecnologia do processo de fabricação. Como os parâmetros analisados afetariam significativamente a densidade da cal hidratada e afetariam menos as outras CQPF, as primeiras ações no processo produtivo partiriam desses dois parâmetros. Os dados da Figura 19 foram alterados para que o conhecimento da empresa fosse protegido.

\section{Resultados do Projeto}

Durante o projeto, a empresa foi adquirida por uma multinacional estrangeira, o que desencadeou diversos acontecimentos, tais como mudança de foco estratégico e remanejamento de cargos. Em função destes fatos, o projeto encerrou-se após a realização de todos os experimentos, sendo analisados e concluídos.

Todas as matrizes foram preenchidas, inclusive a tabela de propostas sementes para melhoria e/ou aquisição de equipamento. No entanto, as ações propostas na linha de produção não foram realizadas até aquele momento. Assim, o projeto do novo produto não foi concluído conforme planejado inicialmente.

Segundo o líder, o projeto possibilitou um melhor entendimento das reais necessidades do seu cliente, do processo de hidratação e do produto cal hidratada. Durante o projeto de QFD informações foram explicitadas, sendo construída uma relação de efeito-causa de todo processo produtivo, em função das reais necessidades do cliente externo (comprador do produto) e interno (própria empresa). Assim, ficou explícito o impacto causado na qualidade do produto e índices de controle por meio de qualquer ação sobre a tecnologia do processo de fabricação e características da matéria-prima.

Outros resultados importantes para a empresa foram os obtidos pelo planejamento e análise de experimentos. Fatores que afetam a densidade do produto foram identificados, e ações para melhoria dessa característica foram propostas.

Figura 18: Planejamento e análise de experimento aplicado junto ao método QFD.

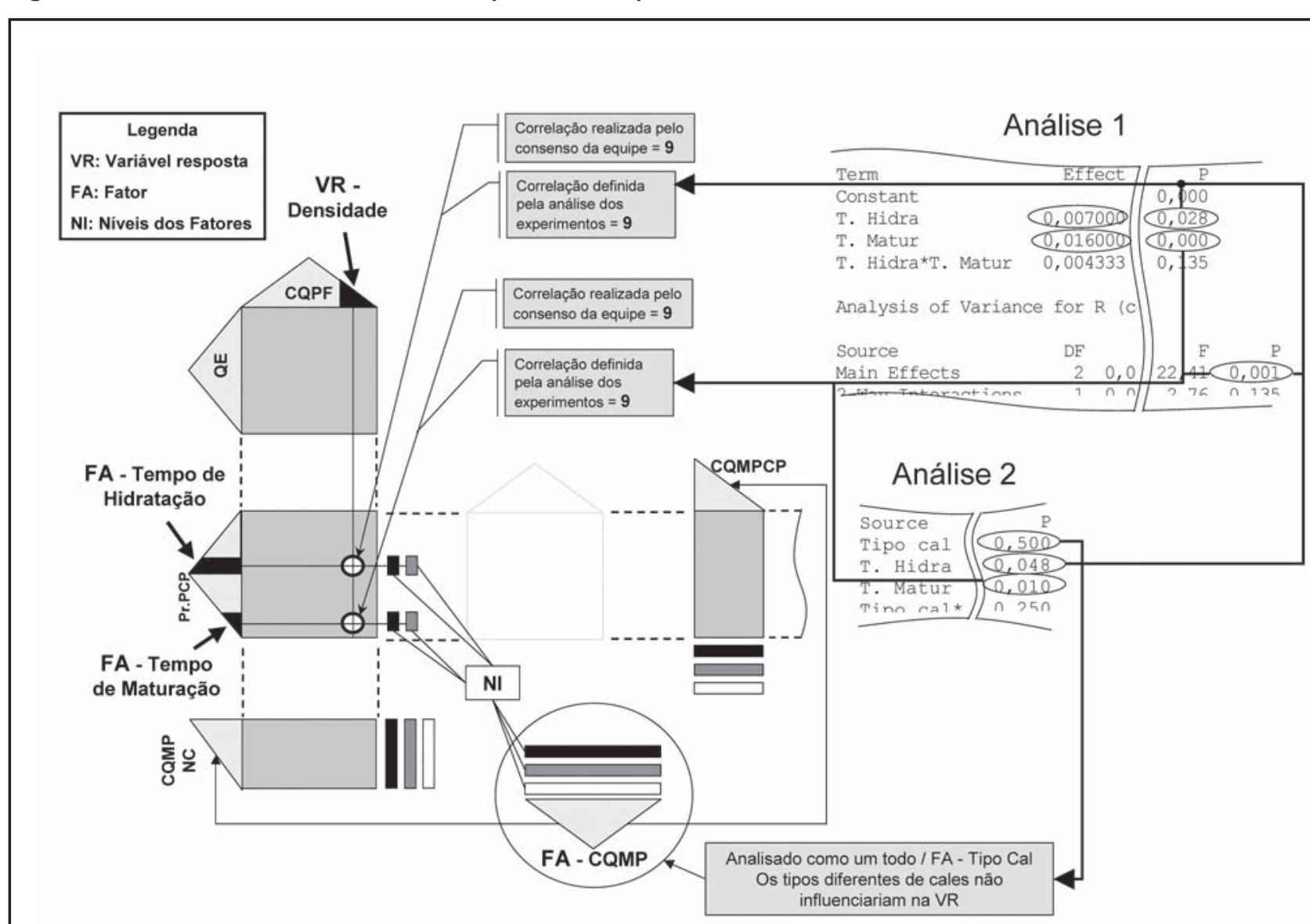




\section{CONCLUSÕES}

Mesmo que o novo produto não tenha sido lançado no mercado até aquele momento, esse trabalho mostrou como o QFD pode ser aplicado no reprojeto de um novo produto em uma empresa de materiais, apesar das particularidades desse segmento.

A realização do desdobramento da tecnologia junto com o desdobramento da qualidade permitiu uma análise de vaivém entre os dois mundos, o que robusteceu o modelo conceitual e aumentou a troca de conhecimento entre as pessoas do grupo de desenvolvimento. O desdobramento da tecnologia mostrou como alterações na tecnologia de fabricação afetam os índices de controle do processo - necessidades do cliente interno. Enquanto, o desdobramento da qualidade revelou como essas mesmas alterações afetam a qualidade do produto final - necessidades do cliente externo. Por ser uma indústria de processos, transformadora de propriedade, e em função dos objetivos da empresa, o mundo da tecnologia é constituído de fatores de fabricação. Os quatro fatores contribuintes utilizados neste caso foram: itens de controle do processo de produção (que são os IDPs referenciados nesse artigo), parâmetro de controle dos processos (esse foi a ponte de ligação entre os dois desdobramentos), equipamentos e propostas para alterações no processo produtivo.

A utilização da ferramenta estatística de planejamento e análise de experimentos como auxiliar ao QFD levantou informações importantes, utilizadas na definição das ações que foram realizadas no processo produtivo (inseridas no mundo da tecnologia) e na definição de correlações (mundo da qualidade).

Utilizou-se o guia de intervenção, apresentado na Figura 2, para auxiliar na operacionalização do QFD. No entanto, situações não tratadas pelo guia surgiram no transcorrer da aplicação, que foram: em que momento deve-se utilizar outros desdobramentos do QFD (como tecnologia além da qualidade positiva) e quais desdobramentos seriam recomendados; quais matrizes deveriam ser incluídas no modelo conceitual, e como o modelo conceitual destes desdobramentos poderia ser construído e associado ao modelo da qualidade positiva; para correlações das matrizes e também obtenção de outras informações (além da especificação de valores), se o uso de técnicas estatísticas é recomendado e qual seria mais apropriada.

Alguns tópicos para trabalhos futuros são: utilização do modelo conceitual adaptado para outras empresas de materiais; aplicação em outras etapas do ciclo de desenvolvimento de produtos e processos; utilização do desdobramento da tecnologia do processo de produção em outros trabalhos; implementação de outros desdobramentos do QFD, como, confiabilidade e custo; utilização de outras técnicas auxiliares ao QFD nesse segmento; e melhoria, ou adaptação para casos específicos, do guia para intervenção apresentado.

Figura 19: Matriz PSMAE x IC.

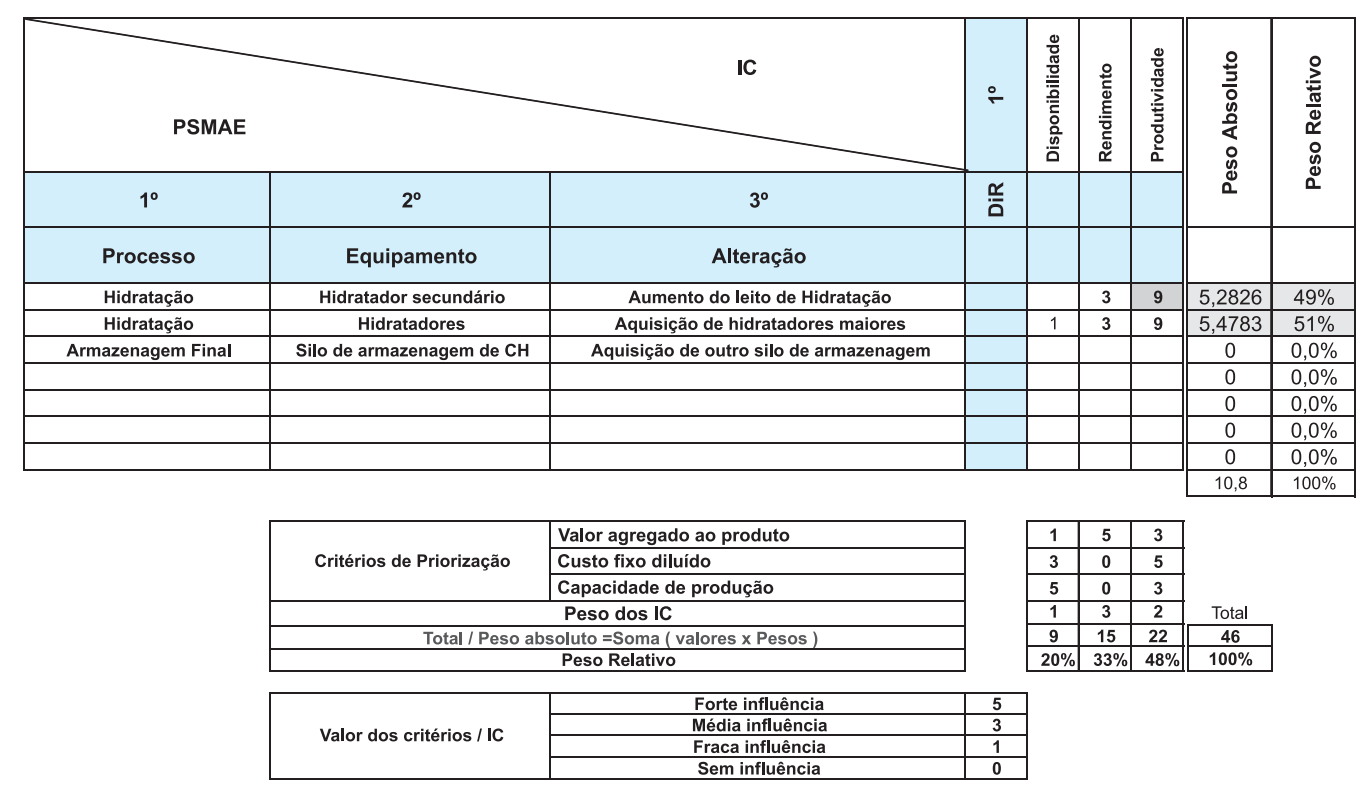




\section{Artigo recebido em 14/06/2007 \\ Aprovado para publicação em 22/11/2007}

\section{- Referências}

AKAO, Y. QFD: integrating customer requirements into product design. Cambridge: Productivity Press, 369 p., 1990.

AKAO, Y. Introdução ao desdobramento da qualidade. Série Manual de Aplicação do Desdobramento da Função Qualidade. v. 1. Belo Horizonte: Editora Fundação Christiano Ottoni, 187 p., 1996.

AKAO, Y.; MAZUR, G. H. The leading edge in QFD: past, present and future. International Journal of Quality \& Reliability Management - The Leading Edge in Quality Function Deployment, v. 20, n. 1, p. 21-35, 2003

AKAO, Y.; NAOI, T. Survey and reviews on Quality Function Deployment in Japan. In: INTERNATIONAL CONFERENCE ON QUALITY CONTROL, 1987, Tokyo. Proceedings of the International Conference on Quality Control. Tokyo: Union of Japanese Scientists e Engineers - JUSE, 1987.

CAUCHICK MIGUEI, P. A.; CARPINETTI, L. C. R. Some Brasilian experiences in QFD application. In: INTERNATIONAL SYMPOSIUM ON QUALITY FUNCTION DEPLOYMENT, $5^{\text {th }} .1999$, Belo Horizonte. Proceedings of the Fifth Annual International Symposium on Quality Function Deployment. Belo Horizonte: Universidade Federal de Minas Gerais - UFMG, p. 229-239, 1999.

CHAN L. K.; WU M. L. Quality Function Deployment: a literature review. European Journal of Operational Research, v. 143, n. 3, p. 463-497, 2002.
CHECKLAND, P. Systems Thinking, Systems Practice. John Wiley \& Sons, Appendix 2. p. 294-298, 1981.

CHENG, L. C. QFD in product development: methodological characteristics and a guide for intervention. Internationa Journal of Quality e Reliability Management. v. 20, n. 1, p. 107-122, 2003.

CHENG, L. C. et al. QFD - planejamento da qualidade. Belo Horizonte: Fundação Christiano Ottoni, 262 p., 1995.

CHENG L. C.; MELO FILHO L. D. R. QFD desdobramento da função qualidade na gestão de desenvolvimento de produtos. São Paulo: Editora Blucher, 539 p., 2007.

CLARK, K. B., WHEELWRIGHT, S C. Managing New Product e Process Development. New York: Free Press, 895 p., 1993.

CLAUSING, D. Total quality development. New York: ASME Press, 506 p., 1994.

COUGHLAN, P. E.; COGHLAN, D. Action research for operations management. International Journal of Operations e Production Management, v. 22, p. 220 240, 2002.

CRISTIANO, J. J.; LIKER, J. K.; WHITE, C. C. Customer-driven product development through Quality Function Deployment in the U.S. and Japan. Journal of Product Innovation Management, v. 17, n. 4, p. 286-308, 2000.
DRUMOND, F. B. Desdobramento da função qualidade (QFD) e métodos estatísticos: uma abordagem integrada para o desenvolvimento de produtos na indústria de processos. 1997, 234p. Tese de Doutorado da Escola de Engenharia da Universidade Federal de Minas Gerais, 1997.

EKDAHL, F.; GUSTAFSSON, A. QFD: the Swedish experience. In: SYMPOSIUM ON QUALITY FUNCTION DEPLOYMENT, 1997, Novi. Transactions from the Ninth Symposium on Quality Function Deployment. Novi: QFD Institute, p. 15-27, 1997.

GRIFFIN, A. Evaluating QFD's use in US fir$\mathrm{ms}$ as a process for developing products. Journal of Product Innovation Management, v. 9, n. 3, p. 171-187, 1992

MARTINS, A.; ASPINWALL, E. M. Quality Function Deployment: an empirical study in the UK. Total Quality Management, v. 12 n. 5, p. 575-588, 2001.

MELO FILHO, L. D. R. Aplicação do método QFD em uma indústria de materiais: desdobramento da qualidade positiva e da tecnologia do processo de fabricação com o auxílio da técnica de planejamento e análise de experimentos. 2005. 167 p. Dissertação Submetida ao Programa de Pós-graduacão em Engenharia de Produção. Belo Horizonte: Universidade Federal de Minas Gerais - UFMG, 2005.

MEYER, M. H.; DALAL, D. Managing platform architectures and manufacturing process for nonassemble products. International Journal of Product Innovation Management, v. 19, p. 277-293, 2002.
MONTGOMERY D. C. Design and analysis of experiments. 4. ed., New York: John Wiley \& Sons, 704 p., 1997.

OLIVEIRA, L. C.; DRUMOND, F. B. Uso integrado do método QFD e de técnicas estatísticas de planejamento e análise de experimentos na etapa do projeto do produto e do processo. In: CONGRESSO BRASILEIRO DE GESTÃO DE DESENVOLVIMENTO DE PRODUTO, 2 o, 2000, São Carlos. Anais do $2^{\underline{0}}$ Congresso Brasileiro de Gestão de Desenvolvimento de Produto. São Carlos: UFSCar, p. 42 49, 2000.

RAPOPORT, R. N. Three dilemmas in action research. Human Relations, v. 23, n. 6, p. 499-513, 1970

ROSS, H. M.; PARYANI, K. QFD status in the U. S. automative industry. In: SYMPOSIUM ON QUALITY FUNCTION DEPLOYMENT, $7^{\text {th }}, 1995$, Ann Arbor. Transactions of the Seventh Symposium on Quality Function Deployment. Ann Arbor: QFD Institute, p. 575-584, 1995.

SHREVE R. N., JUNIOR J. A. B. Indústria de Processos Químicos. 4. ed. Rio de Janeiro: Guanabara Koogan, 717 p., 1997.

SUSMAN, G. I.; EVERED, R. D. An Assessment of the Scientific Merits of Action Research. Administrative Science Quarterly, v. 23, Dec., p. 582603, 1978.

VONDEREMBSE, M. A.; RAGHUNATHAN, T. S. Quality Function Deployment's impact on product development. International Journal of Quality Science, v. 2 n. 4, p. 253-271, 1997.

\section{- Sobre os autores}

\section{Leonel Del Rey de Melo Filho}

QI9 - Qualidade \& Inovação/ NTQI / DEP / UFMG

E-mail: leonel@qi9.com.br

\section{Lin Chih Cheng}

NTQI / DEP / UFMG

Departamento de Engenharia de Produção

E-mail: lincheng@ufmg.br 